\title{
Revisión del traumatismo craneoencefálico
}

\author{
A. Bárcena-Orbe; C.A. Rodríguez-Arias*; B. Rivero-Martín**; J.M. Cañizal-García; C. Mestre-Moreiro; J.C. Calvo- \\ Pérez; A.F. Molina-Foncea y J. Casado-Gómez \\ Servicio de Neurocirugía. Hospital Universitario Central de la Defensa. Madrid. *Servicio de Neurocirugía. Hospital General. Ciudad Real. \\ **Servicio de Neurocirugía. Hospital Niño Jesús. Madrid.
}

\section{Resumen}

En este artículo se ha realizado una revisión sistemática de los aspectos prácticos más destacables del manejo del traumatismo craneoencefálico en base a la literatura médica que hemos considerado relevante. EI trabajo se ha desarrollado en diferentes apartados que comprenden la epidemiología, pronóstico y clasificación, anatomía patológica y fisiopatología, evaluación clínica y tratamiento. Se han tratado con especial énfasis las conexiones entre los rasgos fisiopatológicos con mayor grado de evidencia, de acuerdo con las guías de práctica clínica, y los esquemas de manejo terapéutico.

PALABRAS CLAVE: Traumatismo craneoencefálico. Daño axonal difuso. Metabolismo cerebral. Guías de práctica clínica. Infarto cerebral.

\section{Overview of nead injury}

\section{Summary}

A systematic revision of the main practical aspects related with the head injury management has been made in this article on the basis of relevant literature. The paper has been developed in different sections consisting of epidemiological factors, prognosis and classification, neuropathology and pathophysiology, clinical evaluation and treatment. According to clinical guidelines, the connections between the pathophysiological features with higher evidence degree and the schemes of therapeutic approahes have been emphasized.

KEY WORDS: Head injury. Diffuse axonal injury. Brain metabolism. Guidelines. Brain infarction.

Recibido; 20-03-06. Aceptado: 28-04-06

\section{Epidemiología}

Se puede estimar que la incidencia anual de traumatismo craneoencefálico (TCE) en España es del orden de 200 nuevos casos/100.000 habitantes. El 70\% de éstos tienen una buena recuperación, el $9 \%$ fallecen antes de llegar al hospital, el 6\% lo hacen durante su estancia hospitalaria y el $15 \%$ quedan funcionalmente incapacitados en diferentes grados (moderados, graves o vegetativos) ${ }^{20}$. Por incapacidad funcional entendemos la presencia de alguna alteración neurológica que limita su vida normal en diferente medida, desde la necesidad para su propio cuidado hasta la reincorporación a su ocupación laboral previa ${ }^{20,33}$. Además, a raíz de un TCE, se pueden producir secuelas psicológicas tales como déficit de memoria, inatención, pensamiento desorganizado, desinhibición, irritabilidad, depresión o impaciencia que convertirán al menos a otro $6 \%$ de los no incluidos en la categoría de incapacitados funcionales en inadaptados sociolaborales y familiares, con lo cual la tasa de incapacidad postraumática asciende al $21 \%$. Por otra parte, teniendo en cuenta solamente los accidentes de tráfico como una de las etiologías más frecuentes del TCE, la Dirección General de Tráfico informó que en 2002 hubo en España 171.000 politraumatizados, lo que ha supuesto un coste económico hospitalario de 180 millones de euros. Así pues, el impacto sanitario y socioeconómico del TCE es enorme, constituyendo la primera causa de muerte en los individuos menores de 45 años de edad y la tercera causa en todos los rangos de edad.

Abreviaturas. AVDL: diferencia arteriovenosa de lactato. $\mathrm{AVDO}_{2}$ : diferencia arteriovenosa de oxígeno. BR: buena recuperación postraumática. $\mathrm{CEO}_{2}$ : extracción cerebral de oxígeno. cNOS: óxido nitrico sintasa constitutiva. CSW: síndrome cerebral de depleción salina. CTE: cadena transportadora de electrones. DAI: lesión axonal difusa. EVP: estado vegetativo persistente. FSC: flujo sanguíneo cerebral. GPDH: glicerol 3-fosfato dehidrogenasa. HIC: hipertensión intracraneal. iNOS: óxido nítrico sintasa inducible. LOI: indice lactato/oxígeno. PAM: presión arterial media. $\mathrm{PtiO}_{2}$ : presión tisular de oxígeno. $\mathrm{RLO}$ : radicales libres de oxígeno 


\section{Tabla 1}

Escala de Comas de Glasgow para adultos

\begin{tabular}{lc}
\hline Respuestas & Puntuación \\
Verbal (V) & \\
\hline Orientado & 5 \\
Lenguaje confuso & 4 \\
Palabras inapropiadas & 3 \\
Sonidos incomprensibles & 2 \\
Ninguna & 1 \\
Ocular (O) & \\
Apertura espontánea & 4 \\
A la orden & 3 \\
Al dolor & 2 \\
Ninguna & 1 \\
Motora (M) & \\
Obedece órdenes & \\
Retira al dolor & 6 \\
Flexiona al dolor & 5 \\
Flexión anormal al dolor & 4 \\
Extensión al dolor & 3 \\
Ninguna & 2 \\
Intubado o con traqueostomía & 1 \\
\hline
\end{tabular}

Desde principios de los años 70 existe una manifiesta preocupación en los estamentos públicos para controlar esta verdadera epidemia, una de cuyas metas primordiales es reducir la frecuencia de los accidentes de tráfico. Entre las medidas preventivas cabe mencionar el uso obligatorio de casco y cinturón de seguridad, la incorporación de 'air bag', el control de alcoholemia, la mejora en el diseño de los trazados de carreteras, la adopción de normativas internacionales sobre superestructuras y anclajes, y las campañas de seguridad vial entre otras.

\section{Clasificación y evolución}

Tradicionalmente se incluye bajo la denominación de TCE leve al que tiene una puntuación igual o superior a 13 según la Escala de Comas de Glasgow (GCS) (Tablas 1 y 2) dentro de las primeras 48 horas del impacto y una vez realizadas las maniobras pertinentes de reanimación cardiopulmonar.

Al TCE moderado le corresponde una puntuación entre 9 y 12. Al TCE grave se le asigna una puntuación de 8 ó menos. No obstante, por la evolución y peculiaridades terapéuticas, existe la tendencia de asignar una puntuación mayor o igual a 14 al TCE leve, y una puntuación entre 9 y 13 al TCE moderado. De acuerdo con esta clasificación, y
Tabla 2

Escala de Comas de Glasgow pediátrica

\section{Respuestas}

Puntuación

\section{Verbal (V)}

Sonríe, sigue los sonidos u objetos, interactúa

Llora pero se le puede tranquilizar, interacción inapropiada 4

Se le puede tranquilizar difícilmente, gemidos 3

Inconsolable, agitado 2

No respuesta vocal

\section{$\underline{\operatorname{Ocular}(\mathbf{O})}$}

Apertura espontánea $\quad 4$

A la orden 3

Al dolor $\quad 2$

No apertura de ocular 1

Motora (M)

Obedece órdenes $\quad 5$

Localiza el dolor $\quad 4$

Retirada al dolor 3

Flexión al dolor $\quad 2$

Extensión al dolor $\quad 1$

teniendo en cuenta que existen muchas dificultades de orden epidemiológico, los tres grupos de pacientes podrían distribuirse aproximadamente como sigue: el 12\% sufre un TCE grave, el $16 \%$ se encuadra dentro de los TCE moderados, y el $72 \%$ restante se incluye en la categoría de TCE leve $e^{14,33}$.

Existen muchas variables que determinan el pronóstico del TCE grave: el mecanismo de la lesión traumática, la edad de los pacientes, el estado de las pupilas, la puntuación en la GCS tras realizar las maniobras de reanimación y el tipo de lesión mostrada por la neuroimagen. En lo que concierne al mecanismo, la tasa de buena recuperación (BR) es del 5\% y la de muerte (M) junto con estado vegetativo permanente (EVP) es del $48 \%$ para los ocupantes del vehículo en los accidentes de tráfico; del 7,8\% (BR) $\mathrm{y}$ del $57 \%$ (M+EVP) para los que sufren un atropello; y del $6 \%$ (BR) y del $52 \%$ (M+EVP) para los que sufren una caída. Si se considera la edad (junto con una determinada lesión cerebral, por ejemplo la lesión difusa tipo 2) se han obtenido las siguientes cifras: $10 \%$ (BR) y $20 \%$ (M+EVP) en los pacientes de 40 años de edad o menores, y $0 \%$ (BR) y $54 \%$ (M+EVP) para los mayores de 40 años ${ }^{11}$. Las demás variables se analizarán en los apartados correspondientes.

\section{Patología}

En el TCE se producen una serie de acontecimientos 
fisiopatológicos evolutivos en el tiempo. Aunque esos fenómenos forman un "continuum", pueden destacarse de modo esquemático dos tipos básicos de alteraciones: el daño primario y el daño secundario.

El daño primario ocurre inmediatamente después del impacto y determina lesiones funcionales o estructurales, tanto reversibles como irreversibles. Como reacción al traumatismo, el daño primario puede inducir lesiones tisulares que se manifiestan después de un intervalo más o menos prolongado de tiempo tras el accidente. La respuesta que conduce a este daño secundario incluye pérdida de la autorregulación cerebrovascular, alteraciones de la barrera hematoencefálica, edema intra y extracelular, e isquemia. Esta respuesta cerebral también puede determinar cambios patológicos sistémicos, como distrés respiratorio, diabetes insípida, síndrome de pérdida cerebral de sal o pirexia central. Tales trastornos, junto con otros inherentes al politraumatismo o a una terapéutica inadecuada, amplifican la magnitud del daño secundario.

Veamos a continuación algunas características específicas de los dos tipos de fenómenos mencionados.

\section{Daño cerebral primario}

Se relaciona con el mecanismo y la energía desarrollada en el traumatismo. Por ello, la presencia de una fractura presupone que el impacto ha sido importante y que el paciente es un candidato probable para presentar lesiones intracraneales. El daño primario posee un sustrato microscópico específico: lesión celular, desgarro y retracción de los axones, y alteraciones vasculares. Estos cambios traducen macroscópicamente dos tipos, focal y difuso, de lesión ${ }^{12,14}$ :

Lesión focal. Está condicionada por fuerzas directas transmitidas a través del cráneo. La lesión focal -única o múltiple- ocurre frecuentemente en los polos frontales y temporales, y también en las superficies inferiores de estos lóbulos, donde el tejido nervioso está en contacto con los relieves óseos. El ejemplo más representativo lo constituye la contusión cerebral, que consiste en un área de laceración del parénquima asociada a hemorragia subpial y edema mixto (vasogénico y citotóxico). Puede evolucionar hacia: 1) la resolución espontánea; 2) la formación de un hematoma secundario a la atrición de vasos en el foco de contusión; ó 3) el aumento progresivo de su volumen. Las áreas contundidas producen déficit neurológico por destrucción tisular, compresión del tejido cerebral vecino e isquemia. Son causa de subreactividad cuando alcanzan un volumen suficiente como para producir desplazamiento de masa intracraneal y afectar ulteriormente a la sustancia reticular del tronco encefálico (Figura 1) ${ }^{13}$.

Lesión difusa. Se circunscribe básicamente a la lesión axonal difusa (DAI) y a algunos casos de tumefacción

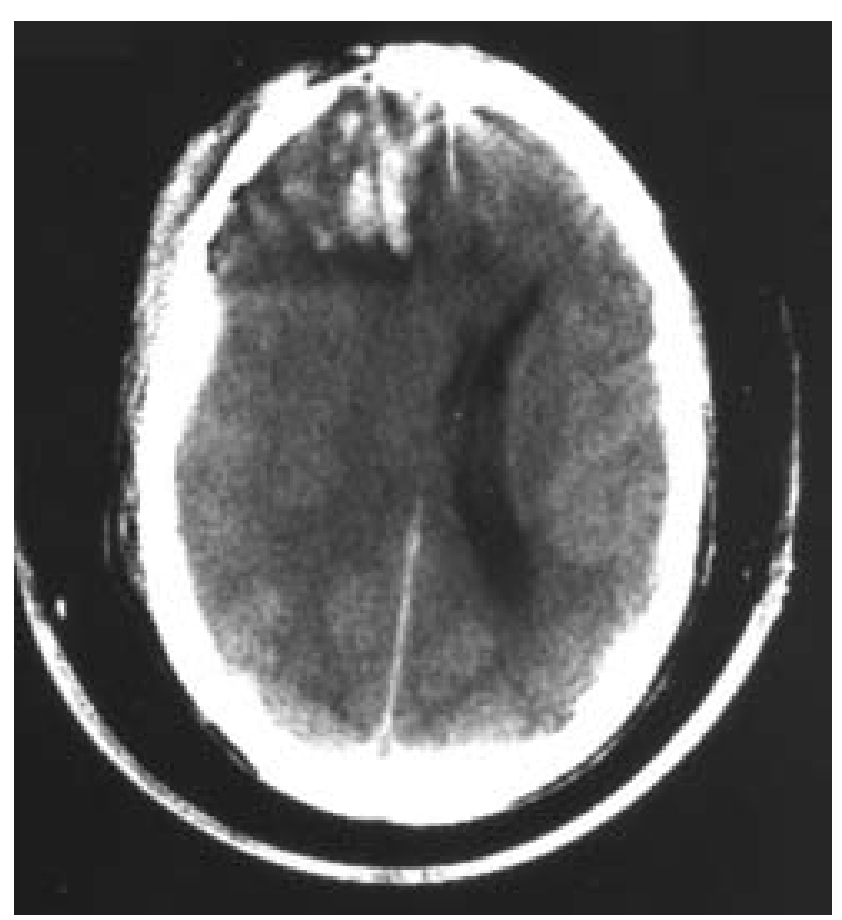

Figura 1. Contusión hemorrágica frontal asociada a swelling hemisférico que determina intenso desplazamiento de la línea media.

("swelling") cerebral difusa, tanto uni como bilateral. La primera se produce por efecto de fuerzas inerciales que actúan sobre los axones durante unos $50 \mathrm{~ms}$ en sentido lineal o angular (i.e, colisiones frontales, lanzamiento rápido de un motorista fuera de su vehículo), pudiendo ocurrir sin impacto relevante sobre el cráneo. Corresponde a esta categoría la presencia de áreas cerebrales más o menos extensas, dañadas como consecuencia de un estiramiento y/o distorsión de los axones que produce per se su desconexión funcional o ruptura física (axotomía primaria). Sin embargo, este tipo de agresión mecánica ocurre en menos del $6 \%$ de las fibras afectadas, puesto que en la mayoría de los axones dañados la lesión no se debe a interrupción anatómica sino a aumento de la permeabilidad para el calcio extracelular en los nodos de Ranvier y en el propio citoesqueleto. El acúmulo de calcio intracelular inicia un proceso que determina la destrucción del axón, pasadas unas horas o días (axotomía diferida).

Tanto en las axotomías primarias como en las diferidas que evolucionan desfavorablemente, los cambios histopatológicos ulteriores son progresivos y se manifiestan como: 1) formación precoz de bulbos de retracción axonal; 2) acúmulo de células microgliales, semanas después; y 3) presencia de largos tractos con fenómenos de degeneración walleriana, al cabo de unos meses ${ }^{13,14}$.

El efecto destructor del mecanismo traumático es más patente cerca de la sustancia blanca subcortical y menos 


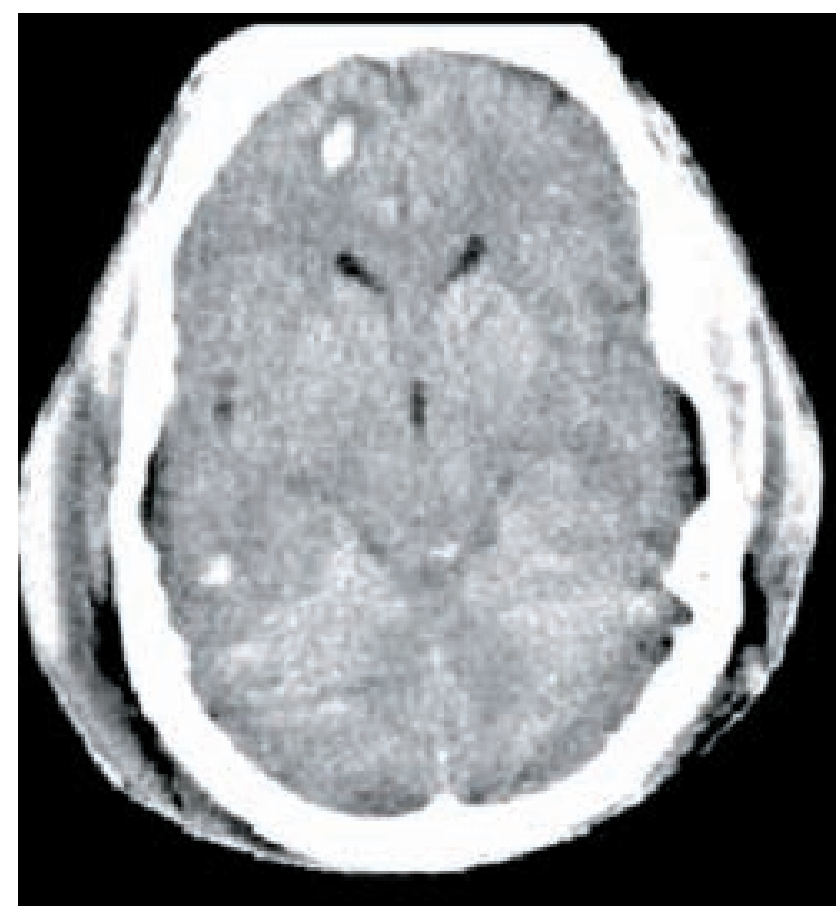

Figura 2.- Lesión axonal difusa. Pueden apreciarse petequias a nivel de la sustancia blanca, cuerpo calloso y tectum mesencefálico.

a nivel del tronco, y la extensión del daño en sentido centrípeto está proporcionalmente relacionada con la aceleración del cráneo en el momento del traumatismo ${ }^{12,13}$. Las alteraciones se localizan preferentemente en los centros semiovales de la sustancia blanca subcortical de ambos hemisferios cerebrales, en el cuerpo calloso, en los cuadrantes dorsolaterales del mesencéfalo, en los pedúnculos cerebelosos, e incluso en el bulbo.

Los pacientes que padecen una lesión difusa están subreactivos desde el momento en que se inflige el traumatismo porque la afectación axonal interrumpe las señales del sistema reticular activador ascendente. Las manifestaciones clínicas incluyen un espectro de presentaciones que van desde la conmoción cerebral (i.e., inconsciencia durante menos de 6 horas) hasta la lesión axonal difusa grave (i.e., inconsciencia durante más de 24 horas con signos de disfunción de tronco). El índice de mortalidad y las secuelas neurológicas se correlacionan con la duración del coma (mayor o menor de 2 semanas) si éste se define como 8 puntos o menos según la $\mathrm{GCS}^{23}$.

Esta modalidad de lesión no puede ser bien demostrada morfológicamente por los procedimientos diagnósticos de neuroimagen, pero, aún pudiendo ser éstos enteramente normales, con frecuencia revelan fenómenos acompañantes como petequias en el cuerpo calloso, pequeños hematomas truncales, y hemorragia subaracnoidea o ventricular. Inicialmente las alteraciones son muy poco relevantes en la TAC,

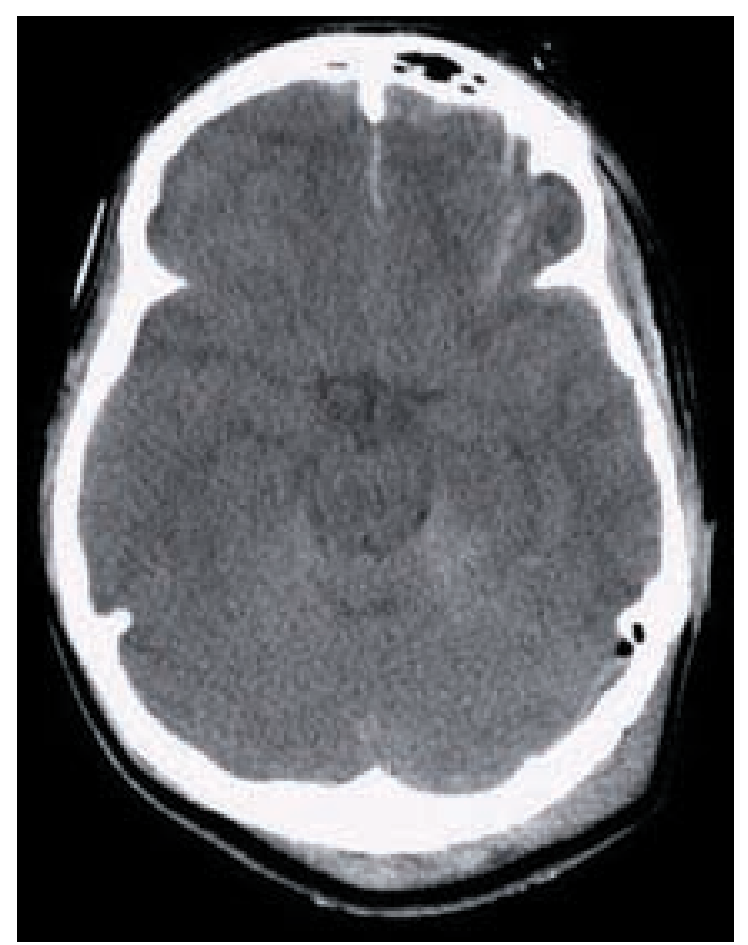

Figura 3. Tumefacción cerebral difusa, que determina obliteración del sistema ventricular y las cisternas peritruncales. Es posible que el parénquima sea discretamente hiperdenso.

puesto que se manifiestan como prácticamente isodensas dado que generan un edema perilesional mínimo, y son petequiales (1-3 mm) tan sólo en el 30\% de los casos (Figura 2). Las imágenes del DAI se vuelven más conspicuas después de la primera semana, a medida que el edema se desarrolla. Éste se origina 1) a partir de la fuga axoplásmica en las neuronas, 2) por extravasación de plasma a nivel de los capilares dañados, y 3) por acúmulo intracelular de agua. La secuencia FLAIR (Fluid Attenuated Inversion Recovery) de la RMN, en la que se atenúa el LCR, es considerablemente más sensible que la TAC para la detección precoz del DAI no hemorrágico, al igual que la secuencia gradiente-eco T2 lo es -menos precozmente- para el DAI hemorrágico, pero es posible que el examen RMN sobrestime la verdadera extensión del daño al poner de manifiesto patología preexistente. Las señales en FLAIR -habitualmente puntiformes e hiperintensas- se localizan con mayor frecuencia en el tronco, sustancia blanca y cuerpo calloso $\mathrm{y}$, a pesar de no existir confirmación histológica, se atribuyen en general a incremento de agua en la vecindad del mayor daño axonal ${ }^{16}$.

Con respecto al "swelling" difuso cabe mencionar que puede presentarse tardía o precozmente, y 1) asociado a otros tipos de lesiones focales (contusiones) y difusas (DAI), ó 2) como entidad única. Cuando se genera durante el curso evolutivo del TCE puede coexistir con 

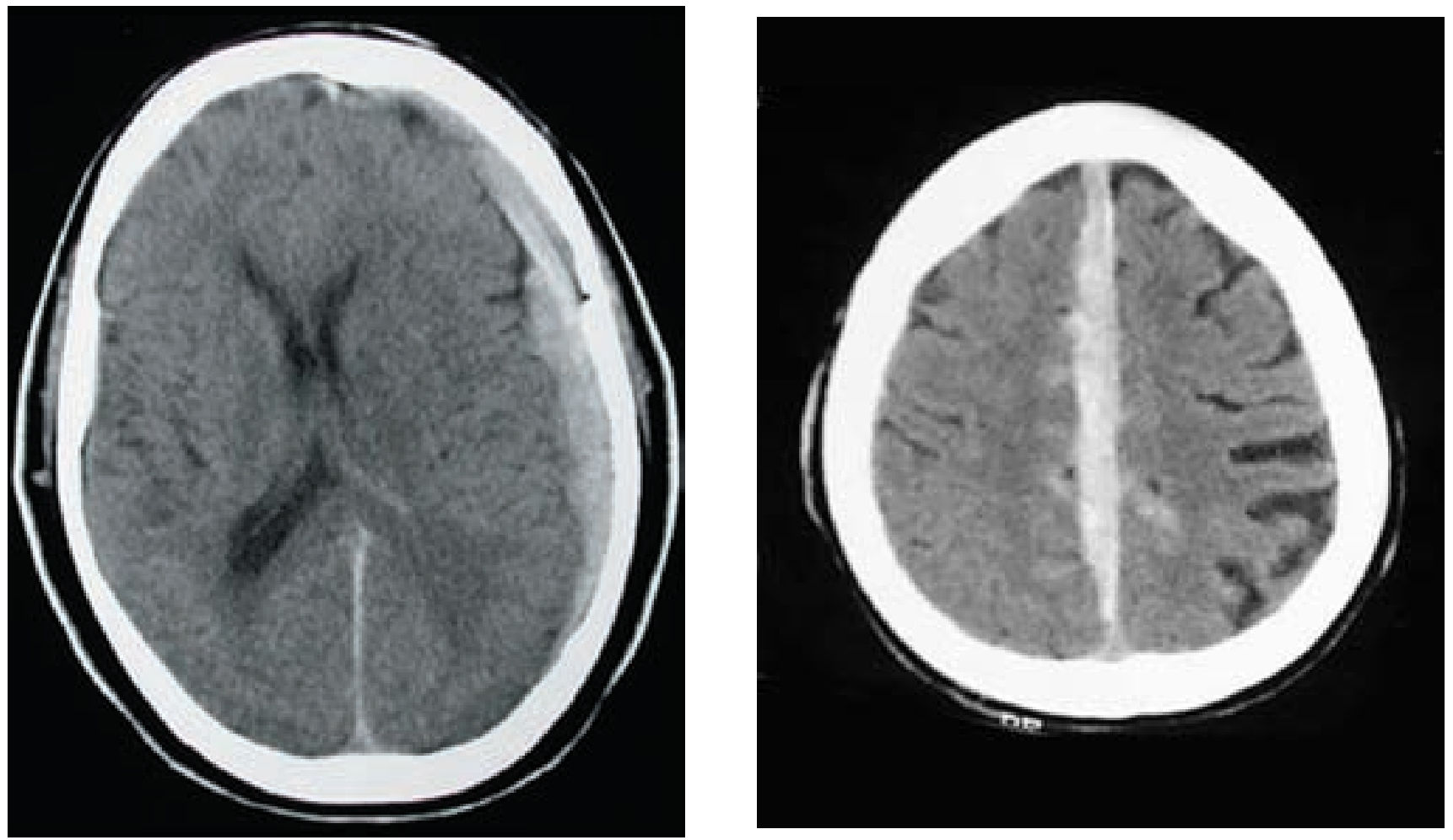

Figura 4. Hematomas subdurales agudos que promueven un desplazamiento sobre las estructuras vecinas congruente con su espesor.

hipertensión intracraneal (HIC) $)^{13,23}$ y acompañarse de otras lesiones anatómicas e isquémicas intracraneales ${ }^{13}$, siendo significativa en su producción la contribución de edema extra y/o intracelular ${ }^{2}$, por lo que en realidad es el resultado de daño cerebral secundario (Figura 1). Sin embargo, en ocasiones se produce aislado y muy precozmente tras el impacto, mostrando la TAC compresión de ventrículos y cisternas y a veces una discreta hiperdensidad global (Figura 3), razón por la cual se ha considerado secundario a vasoplejia ${ }^{38} \mathrm{o}$ a hiperemia ${ }^{23}$. Aunque los datos en humanos sobre los efectos inmediatos del TCE son escasos, hay estudios en modelos animales que sugieren la existencia de un aumento del flujo sanguíneo cerebral (FSC) y del metabolismo global en las primeras horas postraumáticas, con la particularidad de que se produce un exagerado consumo de oxígeno, lo que hace al cerebro particularmente vulnerable a la hipotensión e hipoxia. A este período le sigue otro, de duración variable, en el que disminuye discretamente el FSC y aún más el consumo de oxígeno, lo cual es indicativo de que la 'hiperemia' del cerebro se produce en defecto de sus necesidades metabólicas ${ }^{29,30}$.

\section{Daño cerebral secundario}

Ocurre como respuesta al daño primario y a ciertos eventos sistémicos. En el primer caso se deben consi- derar las lesiones vasculares, que pueden determinar la presencia de hematomas intracraneales (Figura 4), responsables de la elevación de la presión intracraneal (PIC). El aumento patológico de la PIC es la causa local vinculada con mayor especificidad a un incremento del índice de morbimortalidad en el TCE. Igualmente, la duración de la HIC empeora el pronóstico. De hecho, la demora en la evacuación de un hematoma intracraneal significativo posibilita la aparición de secuencias bioquímicas que producen edema vasogénico, edema intracelular e hiperemia (Figura 5). Estas lesiones actúan incrementando aún más la PIC, por el aumento de volumen que acarrean y, además, pueden alterar directamente el metabolismo celular. Por ejemplo, el edema vasogénico secundario a la disrupción de la barrera hematoencefálica -al separar los capilares de las células- perturba el aporte de oxígeno al cerebro induciendo isquemia. Otro factor local vinculado a lesión vascular es el vasoespasmo, que ocurre aproximadamente en el $25 \%$ de los pacientes con hemorragia subaracnoidea postraumática. Si el vasoespasmo se asocia a un aporte sanguíneo bajo puede generar isquemia o infarto cerebral. Cuando en la fase final del período isquémico se produce la revascularización, la hiperoxemia tisular vinculada al mismo posibilitaría la extensión de la lesión más allá del foco o focos isquémicos ${ }^{22,30,31,41}$.

También existe daño secundario en relación con causas 

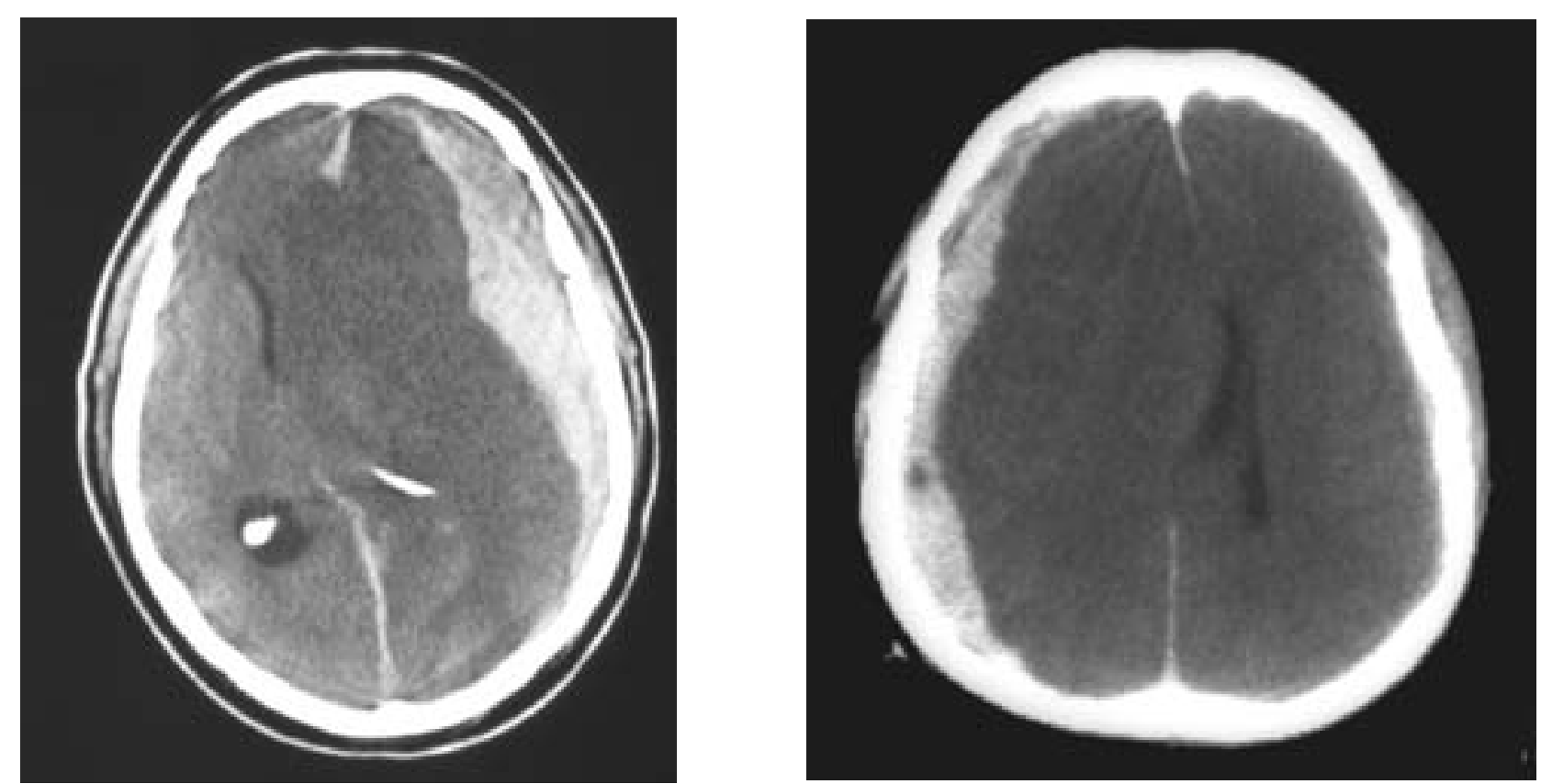

Figura 5. Hematomas subdurales agudos que ejercen un desproporcionado efecto masa debido al swelling acompañante.

sistémicas. De las muchas descritas cabe destacar, como primera variable individual, la hipotensión arterial. Se ha observado que ésta, incluso cuando actúa durante períodos breves, eleva la tasa de mortalidad del TCE grave del $27 \%$ al $50 \%{ }^{5}$. La hipoxemia también empeora el pronóstico. De acuerdo con los resultados del Banco de Datos del Coma Traumático, sin embargo, la hipoxemia aislada aumenta la tasa de mortalidad en torno a un $2 \%$, mientras que ésta se incrementa más de 25 veces cuando se asocia a hipotensión arterial ${ }^{11}$. La fiebre, los estados sépticos y las crisis comiciales aumentan el metabolismo cerebral por lo que los efectos de la isquemia serían, teóricamente, aún más devastadores. Sin embargo, salvo en el caso de fiebre prolongada, no se ha podido demostrar que dichos elementos constituyan variables independientes con alguna influencia significativa sobre el pronóstico del TCE. Por lo que respecta a la hiponatremia, a menudo asociada por diferentes mecanismos al TCE, es un factor determinante de mal pronóstico dado que promueve edema intracelular ${ }^{13,14,30}$.

El control sobre el daño primario en el momento actual -excluyendo las medidas de prevención primaria- no es posible, por lo que minimizar el daño secundario mediante una actuación terapéutica eficaz constituye el objetivo esencial para mejorar el pronóstico del TCE. En este sentido, cobra especial importancia el conocimiento de su fisiopatología y de las medidas que pueden aplicarse para minimizarlo.

\section{Fisiopatología}

Examinaremos las alteraciones básicas que acompañan sistemáticamente al TCE grave, las cuales conciernen al FSC, a la PIC y al metabolismo cerebral.

\section{Alteraciones del flujo sanguíneo cerebral}

El cerebro normal, dada su escasa capacidad para almacenar sustratos, demanda un elevado aporte de oxígeno y glucosa que se satisface mediante un FSC que equivale aproximadamente al 15\% del gasto cardíaco $(25 \mathrm{ml} / 100 \mathrm{~g} /$ min para la sustancia blanca y $70-90 \mathrm{ml} / 100 \mathrm{~g} / \mathrm{min}$ para la gris $)^{51}$. Éste es relativamente constante a pesar de las fluctuaciones de la presión arterial media (PAM), siempre y cuando se encuentre dentro del rango 60-140 mm Hg. Por encima y por debajo de estos límites se producirá edema vasogénico e isquemia, respectivamente.

El FSC (asumiendo que su valor global normal es 50 $\mathrm{ml} / 100 \mathrm{~g} / \mathrm{min}$ ) parece regido por la siguiente función:

$$
F S C=\frac{P A M-P I C}{R}=\text { constante }
$$

donde $\mathrm{R}$, la resistencia de las arteriolas cerebrales, aumentará por vasoconstricción si la PAM se eleva y disminuirá por vasodilatación si la PAM desciende. En todo caso, la diferencia entre PAM y PIC, denominada presión de perfusión cerebral (PPC), debería mantenerse cercana a 60 $\mathrm{mm} \mathrm{Hg}$ puesto que -si es menor- será inevitable un cierto grado de isquemia y -si es mayor- determinará un aumento del volumen sanguíneo intracraneal ${ }^{41}$. En más del 50\% de los pacientes con TCE grave la autorregulación se deteriora focal o difusamente después de las primeras 24 horas del 
impacto y se mantiene así durante 4 ó 5 días, lo cual traduce la desactivación de $\mathrm{R}$ en la notación anterior ${ }^{40}$. Consiguientemente, el FSC seguirá pasivamente los cambios de PAM y PIC. Por tanto, si la PAM disminuye o la PIC aumenta habrá un escaso aporte de sangre al cerebro ${ }^{43}$.

Esta idea tan aparentemente sencilla ha producido dos escuelas de tratamiento radicalmente opuestas. Por un lado, de acuerdo con la teoría de Rosner, la reducción de la PPC, bien por elevación de la PIC bien por disminución de la PAM, activaría una respuesta vasodilatadora cerebrovascular con aumento del FSC. Subsecuentemente, el incremento secundario del volumen sanguíneo cerebral, al quedar progresivamente atrapado en el lecho vascular comprimido por el parénquima hipertenso (debido a la presencia de hematomas, focos contusivos, edema, etc) condicionaría una disfunción de la barrera hematoencefálica con edema intersticial secundario, por lo que la PIC se elevaría aún más. Aquí se preconiza el mantenimiento de una PPC por encima de $75 \mathrm{~mm} \mathrm{Hg}$, empleando incluso aminas presoras para elevar la PAM. Ello daría como resultado una respuesta vasoconstrictora cerebral y reducción de la $\mathrm{HIC}^{37,38,39}$. Como puntos de crítica destacan los siguientes:

a) Se presupone que la autorregulación está indemne, aunque desplazada a la derecha, significando esto que en el TCE son necesarias magnitudes de PPC mucho mayores que las fisiológicas para lograr un FSC apropiado. Sin embargo, otros estudios han demostrado que la mayoría de los pacientes -manejados durante los cuatro primeros días con incrementos de PAM de hasta $14 \mathrm{~mm} \mathrm{Hg}$ - desarrollan aumentos de PIC superiores al $20 \%$ de las cifras previas ${ }^{29}$.

b) No se considera la posibilidad de vasoplejia como posible factor etiológico del "swelling".

c) Sólo se reconocen elevaciones de PIC precedidos de caídas de tensión arterial, como si aquéllos fueran el reflejo de una respuesta fisiológica para mejorar el FSC.

Opuesta a la anterior está la hipótesis de Lund, que identifica el "swelling" postraumático con el edema vasogénico, el cual sería secundario a trastornos de la autorregulación (fundamentalmente vasodilatación) asociados a aumento de la permeabilidad de la barrera hematoencefálica. Sus defensores consideran que la hipertensión arterial facilitaría la filtración transcapilar de fluidos y aumento del edema. En consecuencia, la reducción de las cifras tensionales del capilar por debajo de la presión tisular del parénquima tendría que conducir a una inversión de flujo y a la reabsorción del edema. Por ello preconizan una reducción de la PAM, no inferior a $90 \mathrm{~mm} \mathrm{Hg}$, empleando bloqueantes $\beta_{1}$ adrenérgicos (metoprolol) combinados con agonistas $\alpha_{2}$ (clonidina), y -si existe HIC- con vasoconstrictores venosos (dihidroergotamina). Estas medidas deberían mantener la PPC por debajo del límite inferior de la normalidad (en torno a los $55 \mathrm{~mm} \mathrm{Hg})^{2}$.

Los puntos más controvertidos son: a) La aseveración de que el "swelling" es sólo edema vasogénico, cuando diversos estudios han sugerido que puede corresponder tanto a vasoplejia como a edema intracelular ${ }^{39}$.

b) La afirmación de que la disminución terapéutica de la PPC no produce isquemia 'puesto que el FSC permanece normal', sobre la única base de determinaciones globales del mismo.

c) Los buenos resultados obtenidos aplicando estos principios puesto que -al haberse estudiado en una corta serie de casos relativamente seleccionados- podrían no ser significativos ${ }^{33}$.

Puesto que ambas hipótesis constituyen evidencias parciales construidas sobre una metodología sesgada, su aplicación en la clínica debería emplearse con cautela debido a su riesgo potencial (edema e HIC en la primera e isquemia en la segunda), particularizándose según las circunstancias específicas de cada paciente. En todo caso, las guías de práctica clínica aconsejan mantener la PPC por encima de $60 \mathrm{~mm} \mathrm{Hg}$. Cifras por debajo de $50 \mathrm{~mm} \mathrm{Hg}$ se relacionan con una disminución de la tensión tisular de oxígeno cerebral y aumento de la tasa de morbimortalidad; en cambio cifras inducidas de 70 ó más se asocian a elevaciones de PIC y a una mayor incidencia de distrés respiratorio (Guidelines for the management of severe traumatic brain injury. Brain Trauma Foundation. Updated CPP Guidelines approved by the AANS on March 14, 2003) $)^{5}$.

Otro aspecto interesante del TCE es que la reactividad de las arteriolas frente a los cambios de $\mathrm{pCO}_{2}$ (que depende de una regulación especial promovida por el medio químico en el plasma, en el intersticio y en la célula) está preservada durante gran parte del período en que se desarrollan los cambios promovidos por el TCE $\mathrm{T}^{31,38}$. Esto tiene implicaciones terapéuticas, pues se puede conseguir una disminución de la PIC induciendo vasoconstricción arteriolar (y, por tanto, disminución del volumen sanguíneo cerebral) mediante la hipocapnia secundaria a la hiperventilación. Aunque una hiperventilación agresiva $\left(\mathrm{pCO}_{2} \leq 25 \mathrm{~mm} \mathrm{Hg}\right)$ puede producir isquemia, la posibilidad de que ésta tenga lugar es baja si se cumplen todas y cada una de las siguientes condiciones: 1) que no exista isquemia cerebral global previa (estado que se define como aquél en que la saturación de oxígeno medida en el golfo de la yugular es menor de 55\%); 2) que no se aplique durante las primeras 12 horas postraumáticas dado que es en ese período cuando el FSC está más bajo; y 3 ) que se mantenga solamente hasta que la PIC se sitúe en $20 \mathrm{~mm} \mathrm{Hg}$ dado que su efecto vasoconstrictor sobre las arteriolas piales disminuye 24 horas después de iniciarla ${ }^{29}$.

\section{Alteraciones de la presión intracraneal}

El sistema craneoespinal posee mecanismos fisiológicos 
que amortiguan los aumentos intracraneales de volumen (contusión, edema, hematoma), dirigidos a que la PIC se mantenga en el rango normal de $10 \pm 5 \mathrm{~mm} \mathrm{Hg}$ según una ley como la representada en la Figura 6. En esencia, incluyen la obliteración de las cisternas y ventrículos mediante la evacuación de líquido cefalorraquídeo (LCR) y la expulsión de hasta un 7\% del volumen sanguíneo intracraneal fuera del lecho venoso cerebral. La figura citada pretende esquematizar cómo los sucesivos incrementos volumétricos apenas modifican el rango fisiológico de PIC, de modo que antes de alcanzar un cierto estado crítico el sistema craneoespinal se hallará en fase de compensación espacial, pero más allá del mismo, cualquier aumento de volumen promoverá $\mathrm{HIC}^{26,28}$.

En el comportamiento peculiar de la curva presión/ volumen radica el concepto de complianza craneoespinal: 'capacidad de asumir volúmenes sin que aumente la PIC a valores patológicos'3. Para calcular esta variación de volumen con respecto a la presión existen procedimientos indirectos, como más adelante se verá.

Cuando la complianza se agota, el paciente experimentará un aumento de su PIC, lo cual ocurrirá de forma progresiva o de forma periódica. En este último caso habrá ascensos de 40-80 mm $\mathrm{Hg}$ con una duración de 5 a 20 minutos (ondas A de Lundberg) con intervalos dentro del rango normal (Figura $7 \mathrm{C}$ ). El mecanismo exacto de este patrón de HIC es desconocido.

La importancia clínica de mantener la PIC en niveles de 20-25 mm Hg se debe a lo siguiente: 1) como la autorregulación está a menudo deteriorada, el aumento de PIC reducirá la PPC, por lo que inevitablemente se incrementará la isquemia cerebral preexistente; y 2) la PIC no es homogénea, es decir, existen gradientes que se mantienen por el hecho de que el cráneo está compartimentado por las membranas durales. De este modo, la mayor magnitud de presión se localizará en las áreas donde exista una masa postraumática, que se irá disipando -contrarrestada por el tentorio y la hoz- en los puntos más alejados del foco. Este hecho condiciona desplazamientos de tejido cerebral con

\section{Presión intracraneal}

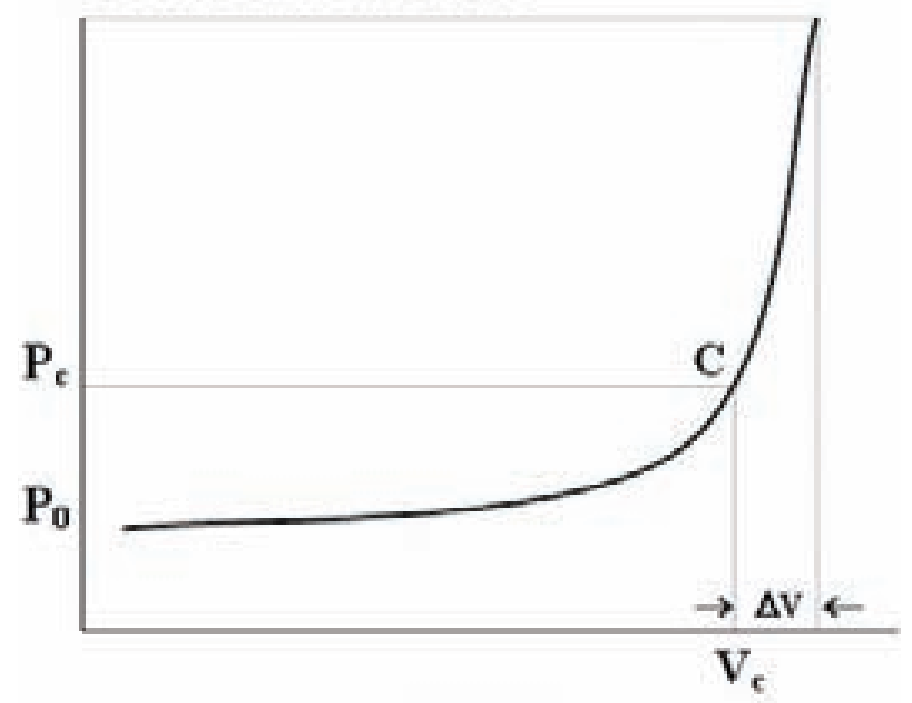

VOLUMEN

Figura 6. Curva que muestra la variación de la presión intracraneal en función del volumen añadido al endocráneo. Cuando los mecanismos amortiguadores del aumento de presión están intactos, el sistema craneoespinal es capaz de admitir hasta un determinado volumen (Vc), manteniéndose la presión intracraneal dentro del rango fisiológico comprendido entre P0 y Pc. Una vez agotados dichos mecanismos, la relación entre la presión y el volumen queda definida en la curva por el punto crítico C. En esta situación, la adición de un mínimo volumen ( $\Delta V)$ al sistema determina un aumento exponencial de la presión.

ulterior compresión del tronco (enclavamiento).

\section{Alteraciones del metabolismo cerebral}

El consumo metabólico cerebral de oxígeno $\left(\mathrm{CMRO}_{2}\right)$

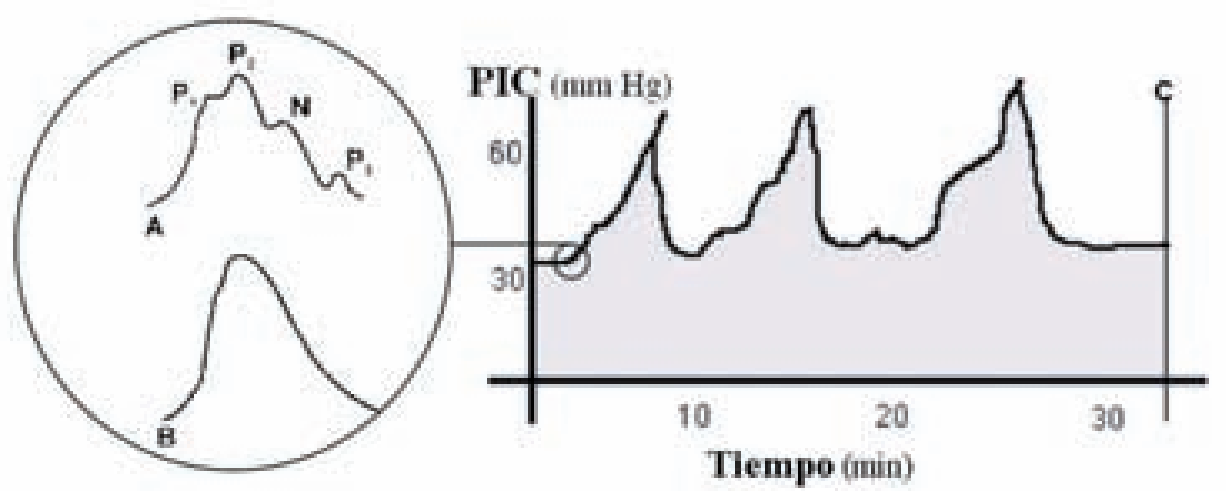

Figura 7. A: Componentes normales de la onda de pulso de la presión intracraneal (armónicos P1, P2 y P3). B: Desaparición de los armónicos, lo que sugiere una disminución de la complianza craneoespinal. $C$ : Registro temporal de la presión intracraneal compatible con un patrón de ondas $A$ de Lundberg. 
equivale al producto del FSC por la diferencia arterioyugular de oxígeno, siendo su valor normal $3,5 \mathrm{ml} / 100 \mathrm{~g} / \mathrm{min}$. En condiciones normales, el cerebro consume oxígeno a razón de $156 \mu \mathrm{mol} / 100 \mathrm{~g} / \mathrm{min}$ y quema glucosa a razón de 26-31 $\mu \mathrm{mol} / 100 \mathrm{~g} / \mathrm{min}$, con un cociente respiratorio cercano a la unidad ( $1 \mathrm{~mol} \mathrm{de} \mathrm{O}_{2}$ produce $1 \mathrm{~mol} \mathrm{de} \mathrm{CO}_{2}$ ). Cuando el FSC decae, el $\mathrm{CMRO}_{2}$ se mantiene inicialmente dentro de la normalidad a costa de producirse una mayor extracción de oxígeno (aumenta la diferencia arterioyugular de oxígeno). Pero si el flujo sigue disminuyendo, el efecto compensador de la extracción resulta insuficiente y aparece la isquemia. Ésta, en el TCE grave, se debe a una reducción del FSC en relación con daño anatómico directo de los vasos, espasmo vascular y tumefacción endotelial que disminuye el calibre de las meta-arteriolas. Por su parte el $\mathrm{CMRO}_{2}$ disminuye proporcionalmente a la profundidad del coma. Idealmente la reducción del FSC debería acompañarse de una disminución paralela del $\mathrm{CMRO}_{2} \mathrm{y}$, si esto ocurriese de forma perfectamente acoplada, declinaría progresivamente tan sólo la vitalidad de las células dañadas irreversiblemente hasta producirse la necrosis de las mismas. Sin embargo, tal acoplamiento muchas veces no existe y a ello es debida la extensión del daño inicial ${ }^{43}$. Veamos los fenómenos que han probado ser relevantes a este respecto.

El requerimiento energético de la neurona es muy alto a causa de la intensa actividad que sus bombas iónicas realizan para llevar a cabo secuencias de polarización/ despolarización hiper-rápidas. El cerebro depende de un suministro casi constante de oxígeno y glucosa, la cual es su principal fuente de energía, almacenándose ésta fundamentalmente en moléculas como adenosin trifosfato (ATP), dinucleótido de nicotinamida adenina (NADH) y dinucleótido de flavina adenina $\left(\mathrm{FADH}_{2}\right)$. La glucosa se metaboliza en el citoplasma celular -sin oxígeno- hasta transformarse en dos moléculas de piruvato, el cual puede seguir dos caminos: catabolizarse en el citoplasma, a través de una vía anaerobia con poca liberación de energía (la mayoría de la energía que podría aportar la glucosa se pierde en forma de metabolitos), o ingresar en la matriz mitocondrial y liberar casi 20 veces más de energía.

La preponderancia de una u otra alternativa depende de la presencia de oxígeno en cantidad adecuada y de la integridad de la maquinaria oxidativa mitocondrial.

Si alguno de estos requisitos no se cumple, entonces el catabolismo se verifica haciendo que el piruvato actúe como aceptor terminal de los electrones del NADH (forma reducida del cofactor), con lo que se obtiene lactato, protones y $\mathrm{NAD}^{+}$(forma oxidada del cofactor). Dado el bajo rendimiento de esta reacción, el acúmulo de lactato es enorme pues se necesitan muchas moléculas de glucosa para que la célula obtenga la energía necesaria. Por el contrario, si los requisitos se cumplen, el piruvato se oxida completamente transformándose en $\mathrm{CO}_{2} \mathrm{y}$ agua dentro de la matriz, donde

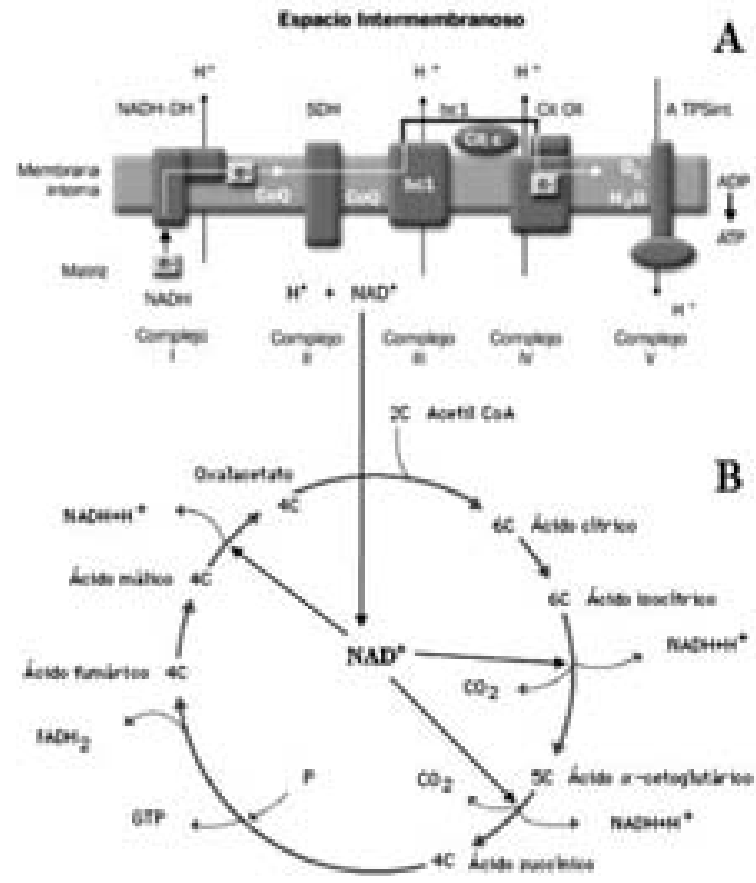

Figura 8. Cadena transportadora de electrones (A) y ciclo de Krebs (B), modificado de Zauner A y cols $^{51}$ (véase texto).

el oxígeno molecular actúa como aceptor terminal de los electrones del NADH.

Esta oxidación se realiza escalonadamente, de tal modo que la energía se libera en paquetes discretos, realizándose el proceso del siguiente modo: mediante la acción de la piruvato decarboxilasa, el piruvato se convierte en acetil $\mathrm{CoA}$, el cual genera citrato en el ciclo de Krebs (Figura $8 \mathrm{~B}$ ), lo que posibilita la formación de $\mathrm{CO}_{2}$, ATP, NADH y $\mathrm{FADH}_{2}$, con regeneración ulterior de citrato, para reiniciarse el ciclo en forma autorregulable. Éste se potencia cuando la concentración de ADP aumenta (es decir, cuando la célula consume energía), y se detiene cuando los niveles de NADH se elevan ${ }^{51}$. Así pues, la célula necesita oxidar constantemente $\mathrm{NADH}$ y convertirlo en $\mathrm{NAD}^{+}$para que el ciclo funcione ininterrumpidamente. La oxidación del $\mathrm{NADH}$ y la regeneración de $\mathrm{NAD}^{+}$se lleva a cabo en la propia membrana interna mitocondrial según la reacción:

$$
\mathrm{NADH}+\mathrm{H}^{+} \rightarrow \mathrm{NAD}^{+}+2 \mathrm{H}^{+}+2 \mathrm{e}^{-}
$$

que, catalizada por la glicerol 3-fosfato dehidrogenasa $(\mathrm{GPDH})$, libera la energía que cede a los electrones (Figura $8 \mathrm{~A})$.

La membrana tiene cinco complejos lipoprotéicos con afinidad electrónica alta. Un electrón con mucha energía penetra en el complejo I de la misma (ubiquinona), y va pasando -uno tras otro- hasta el complejo IV (Figura $8 \mathrm{~A}$ ). 
En la transferencia de un complejo a otro, los electrones disminuyen ligeramente su nivel energético. Esta energía permite el bombeo de un protón a través de los complejos I, III y IV (el resto de la membrana es impermeable a los protones), con lo cual se crea un gradiente electroquímico con mayor concentración de $\mathrm{H}^{+}$fuera que dentro de la matriz. Además, dado que siempre se están perdiendo electrones y protones, la reacción anterior está desplazada a la derecha, lo que permite que en todo momento exista oferta de protones en la matriz. Cuando los electrones llegan al complejo IV (citocromo oxidasa), el grupo hemo de ésta capta cuatro electrones que, tras reducir su ion férrico a ferroso, son cedidos al oxígeno molecular de la matriz, formándose agua como residuo perfecto:

$$
4 \mathrm{H}^{+}+\mathrm{O}_{2}+4 \mathrm{e}^{-} \rightarrow 2 \mathrm{H}_{2} \mathrm{O}
$$

El complejo IV sólo puede ceder un electrón cada vez al oxígeno, por lo que en la primera transferencia éste se convierte en anión superóxido $\left(\mathrm{O}_{2}\right)$, el cual puede aceptar más electrones o participar en otras reacciones de oxidación. En condiciones normales, hasta que los cuatro electrones no han sido transferidos, es decir, hasta que cada molécula de $\mathrm{O}_{2}$ no se ha reducido completamente a dos moléculas de agua, la citocromo oxidasa atrapa alrededor del $96 \%$ del $\mathrm{O}_{2}$ entre un átomo de hierro y otro de cobre, evitándose de este modo que el superóxido actúe. Una vez formadas las moléculas de agua, éstas difunden libremente desde el complejo a la matriz. En los distintos niveles de la cadena, el $4 \%$ restante del oxígeno toma un electrón por molécula de oxígeno reduciéndose a $\mathrm{O}_{2}$, o bien dos electrones por molécula convirtiéndose en agua oxigenada ${ }^{36}$. Estos radicales se eliminan mediante sistemas enzimáticos reductores.

Finalmente, el intenso gradiente de protones permite el reingreso mitocondrial de éstos a través del complejo V (ATPasa), y parte de la energía liberada en la oxidación del NADH se recupera almacenándose en el ATP que se sintetiza -mediante fosforilación oxidativa- a partir de ADP celular y fósforo inorgánico (Figura $8 \mathrm{~A}$ ).

Existen muchos factores que afectan la función mitocondrial: la sobrecarga intracelular de $\mathrm{Ca}^{2+}$ disminuye la permeabilidad selectiva de su membrana de modo que penetran en su interior diferentes iones provocando tumefacción; sustancias como el ácido cianhídrico, el óxido nítrico o el monóxido de carbono interaccionan con alguno de los complejos de la cadena transportadora de electrones (CTE) en detrimento de su función; la isquemia provoca que su mecanismo decline progresivamente hasta detenerse por completo; TCEs previos también la dañan estructuralmente; determinadas alteraciones genéticas son capaces de modificar el fenotipo de los complejos y actuarán deficientemente. El denominador común de estas circunstancias -y particularmente de la isquemia- consiste en la producción de radicales libres de oxígeno (RLO) tales como hidroxilo $\left(\mathrm{OH}^{-}\right), \mathrm{O}_{2} \cdot$ y agua oxigenada, los cuales son especies químicas muy inestables que pueden reaccionar fácilmente con muchas moléculas que forman parte de las organelas celulares. Parte de los RLO son eliminados con ayuda de scavengers como la vitamina E (que neutraliza al radical hidroxilo) o enzimas intracelulares como la catalasa (que transforma $\mathrm{H}_{2} \mathrm{O}_{2}$ en agua y oxígeno) o la superóxido dismutasa (que suprime el $\mathrm{O}_{2}$ ).

En los leucocitos no macrófagos, astrocitos y células endoteliales existe una enzima, la óxido nítrico sintasa constitutiva (cNOS), cuyo papel es mantener dentro de un límite fisiológico las cifras de NO mediante un mecanismo de autorregulación recíproca. La acción de la cNOS constituye un método apropiado para prevenir el fallo energético de la célula, dada la acción vasodilatadora del NO cuya síntesis cataliza ${ }^{47}$.

La hipoxia-isquemia y la agresión mecánica de las membranas celulares facilitan la liberación en exceso de glutamato. Este neurotransmisor actúa sobre múltiples receptores de tipo N-metilo, y cuando lo hace sobre los que no poseen afinidad por el aspartato (no NMDA) produce intensa despolarización celular, que condiciona la entrada masiva de $\mathrm{Na}^{+} \mathrm{y}$ agua $\mathrm{y}$, en consecuencia, la aparición de edema citotóxico. Este tipo de edema intracelular se produce en las neuronas y en el endotelio. Ya hemos mencionado que la tumefacción endotelial reduce el calibre de las arteriolas finas y posibilita la aparición de isquemia. Por otro lado cabe mencionar que las acuaporinas (AQP) clásicas, familia de proteínas tetraméricas que confieren una permeabilidad selectiva para el agua muy alta (del orden de $10^{9}$ moléculas. $\mathrm{s}^{-1}$ ), pueden ser las responsables de un incremento anormal de agua intraglial en el cerebro isquémico y traumático. Concretamente, en cerebros de rata sometidos a isquemia, la AQP9 se encuentra hiper-expresada en los astrocitos -pero no en las neuronas- del borde del infarto, en los axones y en el hipotálamo, presentando dichas estructuras una tumefacción celular patológica ${ }^{52}$.

La entrada de calcio en la célula parece estar vinculada al ingreso de sodio. Posiblemente el glutamato y otros neurotransmisores -al actuar sobre receptores $\mathrm{N}$-metilo con afinidad por el aspartato (NMDA)- posibilitan la entrada lenta de sodio y de grandes cantidades tiempo-dependiente de calcio. De acuerdo con evidencias experimentales, tejido cerebral en un medio con un bloqueante de los canales de sodio (tetrodotoxina) evolucionó mejor y con una menor concentración intracelular de $\mathrm{Ca}^{2+}$ que otra muestra cultivada sin bloqueante ${ }^{48}$.

El acúmulo de calcio intracelular influye en los macrófagos y neutrófilos, sobre los que promueve la activación de la óxido nítrico sintasa inducible (iNOS), una enzima contenida en dichas células que -a diferencia de la cNOS- no puede frenarse, por lo que produce 


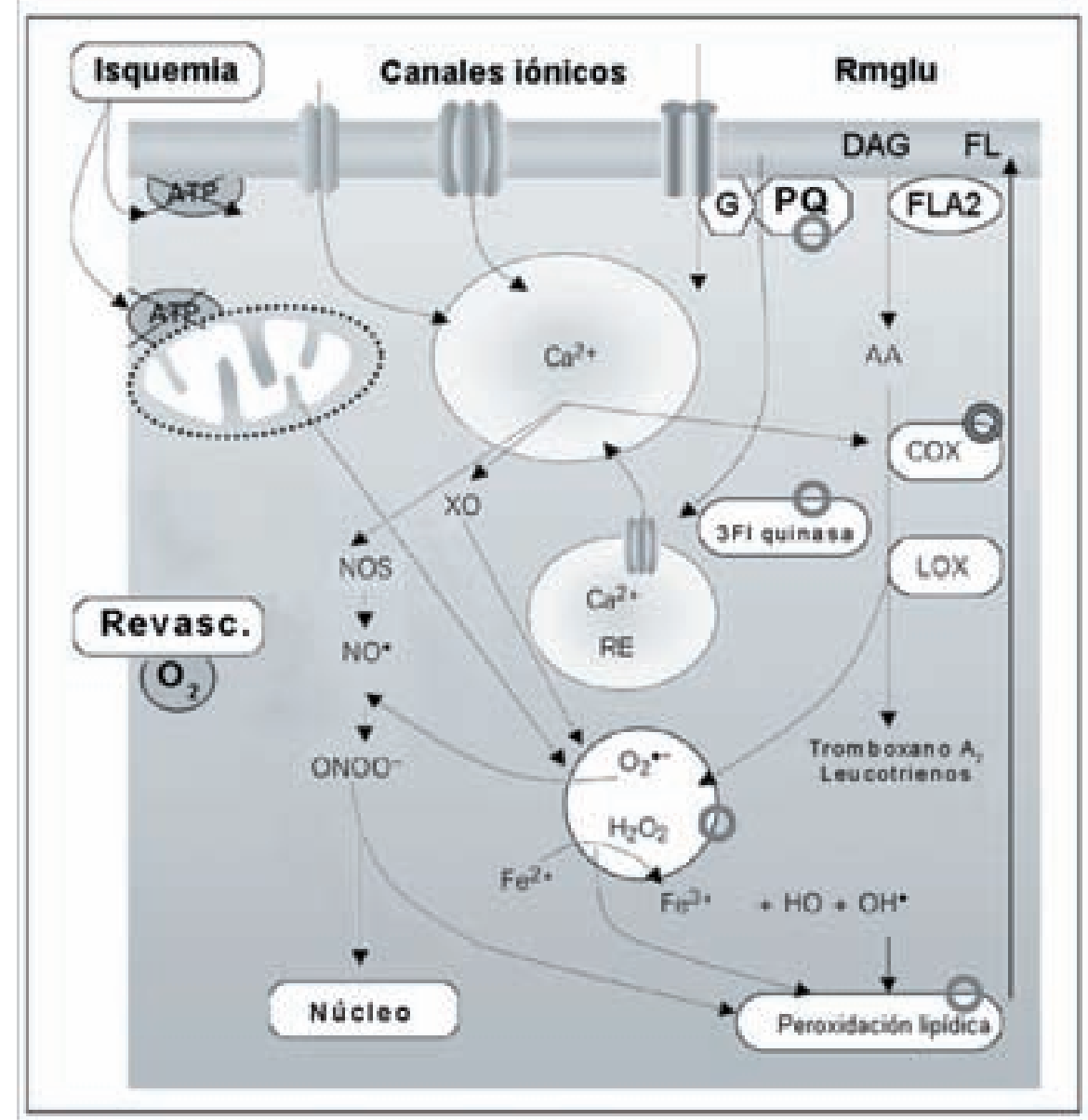

Figura 9. Esquema del proceso isquémico a nivel celular. El fallo metabólico inicial de la mitocondria (reducción de ATP) conduce a una disrupción funcional de los canales iónicos de membrana y liberación masiva de neurotransmisores y glutamato, lo que provoca incremento de la entrada de $\mathrm{Ca}^{2+}$ e hiperexpresión enzimática (XO, NOS, COX, LOX quinasas). Las proteinas $G$ amplifican las señales transmembrana inducidas por los neurotransmisores, regulando la hidrólisis de fosfatidilinositol y la activación de las fosfolipasas. La producción ulterior de especies reactivas de oxígeno y nitrógeno $\left(\mathrm{O}_{2}\right.$, $\mathrm{NO}$, peroxinitrito y $\mathrm{H}_{2} \mathrm{O}_{2}$ ) forma parte del proceso oxidativo celular. La peroxidación lipídica, el daño nuclear y el ataque a distancia del foco isquémico se potencian en la revascularización (Revasc.), estado en el que existe un hiperaflujo relativo de $\mathrm{O}_{2}$ con respecto a la capacidad metabólica mitocondrial (véase texto).

3FI quinasa: 3-fosfatidilinositol quinasa; AA: ácido araquidónico; COX: ciclooxigenasa; DAG: diaglicerol; FL: fosfolípidos de membrana; FLA2: fosfolipasa A2; G: proteina G; LOX: lipooxigenasa; NO: óxido nitrico; NOS: óxido nitrico sintasa; $P Q$ : proteínquinasa C; RE: retículo endoplásmico; Rmglu: receptores metabotrópicos de glutamato; XO: xantino oxidasa.

cantidades elevadas de $\mathrm{NO}^{27}$. Éste provoca importante vasodilatación pues, al estar la autorregulación abolida, los mecanismos vasoconstrictores fisiológicos (excluyendo la disminución de $\mathrm{pCO}_{2}$ ) no se oponen al estímulo del NO. Cuando su efecto sobre los vasos es máximo, se produce vasoplejia, situación en la que ya no responden a ningún estímulo, incluyendo la hipocapnia. Durante este período de revascularización, condicionado por el aumento de NO tras la fase de isquemia, la reintroducción de $\mathrm{O}_{2}$ en el cerebro hipometabólico conduce a un desacoplamiento entre demanda metabólica (baja) y aporte de $\mathrm{O}_{2}$ (alto). Esto desencadena una serie de fenómenos responsables de 1) la destrucción de las zonas de penumbra, y 2) la propagación del daño más allá del área traumatizada ${ }^{47}$. (Figura 9):

1) Como la mitocondria conserva todavía alguna función, el hiperaflujo de $\mathrm{O}_{2}$ reactiva parcialmente la CTE: el catabolismo se desvía de nuevo desde la vía glicolítica anaerobia hasta el ciclo de Krebs y se produce un reacoplamiento de la CTE. No obstante, ésta actúa deficientemente porque el NO bloquea los complejos III y IV. Otra razón de su deficiencia quizá dependa de que se produzca un descenso brusco en la actividad del complejo I tras la 
revascularización (36).

A causa de su funcionamiento inadecuado, se suma a la producción actual de radicales los que se formaron cuando comenzó a declinar la glicolisis aerobia, y todos ellos actuarán destruyendo -más rápidamente que la isquemiaporciones vitales de la célula en las áreas de penumbra dado que se desbordan los sistemas enzimáticos encargados de reducirlos.

2) En el período isquémico, el ADP no utilizado para formar ATP se degrada en AMP y adenina, extrayéndose así toda la energía de los enlaces fosfóricos. La adenina queda finalmente en equilibrio reversible con su metabolito hipoxantina, la cual no es citotóxica. La sobrecarga intracelular de calcio transforma la xantino dehidregenasa en xantino oxidasa que, en ausencia de oxígeno, resulta inactiva. Cuando tiene lugar la revascularización, el oxígeno permite que la xantino oxidasa catalice irreversiblemente el paso de hipoxantina a xantina y ácido úrico. En el transcurso de estas reacciones se libera una inmensa cantidad de superóxido. Este radical reacciona con el NO y genera peroxinitrito, el cual posee una vida media de 1-2 $\mathrm{s}$ y difunde en un radio de $100 \mu$. Ello le permite penetrar en el núcleo, e incluso en otras células, fuera de la que le dio origen, destruyendo porciones de ADN, ARN y otros componentes moleculares ${ }^{22,36}$.

En resumen, bien por acción mecánica bien por isquemia, algunas áreas cerebrales quedarán irreversiblemente dañadas minutos a horas después del traumatismo, mientras que otras se alterarán tan sólo funcionalmente. Estas últimas podrían ser recuperadas si las condiciones metabólicas sistémicas fueran óptimas. En caso contrario, es decir, si se añaden factores isquemizantes o se agrega exceso de oxígeno en la fase de revascularización, se producirán reacciones bioquímicas secuenciales que conducirán a la muerte celular ${ }^{15}$. Ésta se produce por tres mecanismos: axonotmesis diferida, necrosis, y daño mediado genéticamente.

\section{Axonotmesis diferida}

El exceso de calcio intracelular induce un incremento de la actividad de proteasas específicas, las calpaínas, que actúan desorganizando los microtúbulos y neurofilamentos, pudiendo conducir al bloqueo del flujo axonal, inicialmente, y a la destrucción del axón, a las pocas horas ${ }^{24}$. Las calpaínas son -a través de la degeneración retrógrada que indirectamente inducen- uno de los factores responsables de la atrofia cerebral postraumática ${ }^{19}$.

La acción del glutamato sobre los receptores NMDA provoca acúmulo de calcio intracelular por lo que, teóricamente, impedir la acción de este neurotransmisor con antagonistas como Selfotel (competitivo), D-CPPene (competitivo) o Enadoline (presináptico) sería un objetivo para minimizar el efecto de su acción excitotóxica. Sin embargo, las impresiones clínicas obtenidas al respecto parecen poco prometedoras $\mathrm{s}^{42,45}$. Experimentalmente, cuando se consigue bloquear la entrada de calcio, los fenómenos histológicos que ocurren en la axotomía diferida consisten en ondulación de los axones inmediatamente después del traumatismo que -en su mayoría- reasumen la orientación previa en un período de unos 20 minutos, con ulterior restitución funcional. No hay evidencia clínica tampoco de que los calcioantagonistas o los bloqueantes de sodio mejoren el pronóstico de la $\mathrm{DAI}^{45}$.

\section{Necrosis celular}

La superóxido dismutasa convierte el $\mathrm{O}_{2}$ en agua oxigenada, la cual es destruida por la catalasa. Sin embargo, si existe ion ferroso (procedente, por ejemplo, de la hemoglobina extravasada en la hemorragia postraumática) en presencia de $\mathrm{pH}$ tisular bajo, éste se oxida a férrico y el agua oxigenada se transforma en $\mathrm{OH}^{-}$. Este ion hidroxilo altera la configuración espacial de los fosfolípidos de las neuronas, astrocitos y probablemente del endotelio, pasando sucesivamente de una molécula lipídica a otra a lo largo de la membrana hasta alterar la totalidad de las mismas (peroxidación lipídica). La vitamina E es capaz de interponerse entre cada dos moléculas de fosfolípidos, inactivándose por oxidación, a la vez que convierte al $\mathrm{OH}^{-}$en agua, y reactivándose ulteriormente gracias a la vitamina $\mathrm{C}$, a la que oxida y consume en el proceso ${ }^{32}$. A este respecto, uno de los autores ha observado en modelos de isquemia cerebral que, siempre que la concentración plasmática de vitamina $\mathrm{C}$ se encuentra dentro de un determinado rango, no es necesario aportar vitamina $\mathrm{E}$ pues ésta se mantiene en concentraciones adecuadas simplemente con el aporte que supone la ingesta normal. Sin embargo, si la vitamina C -que en el modelo estudiado disminuye constantemente por consumo- no se repone, los niveles de vitamina E tienden a situarse en el límite más bajo de la normalidad ${ }^{36}$.

Por otro lado, el aumento intracelular de $\mathrm{Ca}^{2+}$, la conversión de $\mathrm{O}_{2}$ en $\mathrm{O}_{2}$ hiperreactivo (secundariamente al descenso del $\mathrm{pH}$ condicionado por la acumulación de lactato durante la isquemia) y la trombina generada a nivel de la sangre extravascular activan la síntesis de fosfolipasas, las cuales oxidan las moléculas grasas -desestructuradas por el hidroxilo- produciéndose una elevación de ácido araquidónico. Éste estimula la actividad de la 5-lipoxigenasa y de la cicloxigenasa. La primera de estas enzimas es responsable de la producción de leucotrienos que promueven el acúmulo de neutrófilos a nivel de las membranas lisadas. Éstos poseen un elevado contenido de NADPH oxidasa, la cual actúa sobre los productos de degradación formando superóxido. La cicloxigenasa provoca un aumento de tromboxano A2 que, por su acción agregante plaquetaria, 
favorece ulteriores fenómenos trombóticos e isquémicos. La traducción de este ataque oxidativo sobre la neurona y el astrocito es la disfunción inicial de la membrana -con la consiguiente disrupción de los gradientes iónicos- y finalmente la lisis de la misma que conduce a la necrosis celular (Figura 9). El resultado del ataque al endotelio capilar es su destrucción con la subsiguiente hemorragia, perpetuando todo ello la cascada de eventos descritos ${ }^{36}$. Es interesante el hecho de que en la peroxidación lipídica se liberan cantidades de malonildialdehido en relación directa con el número de moléculas grasas catabolizadas, por lo que su determinación analítica en el bulbo de la yugular ha resultado útil para evaluar el grado de estrés oxidativo agudo que está sufriendo el cerebro ${ }^{30}$.

A modo de ilustración se puede mencionar el hecho de que la neuroimagen secuencial permite apreciar con frecuencia cómo en el DAI se va incrementando progresivamente el daño vascular, aumentando en las primeras 24 horas el número de puntos hemorrágicos cerebrales ${ }^{15}$.

Se han empleado algunos 21-aminoesteroides (Tirilazad) para neutralizar los RLO, y también fármacos para bloquear los canales de sodio (Fosfentoina y Piracetam). Aunque algunos estudios clínicos han sugerido un modesto beneficio en el pronóstico con su empleo, aquél no ha resultado significativo ${ }^{30,47}$. Otros medicamentos, como el pentobarbital sódico y el propofol han demostrado ser capaces de mejorar la $\mathrm{HIC}^{7}$. Este efecto podría ser debido a que reducen el $\mathrm{CRMO}_{2}$ y el CRMglucosa (actúan como scavengers de RLO, inhiben la quimiotaxis de los neutrófilos, y activan la recaptación de glutamato). No obstante, su acción sobre la PIC también podría deberse a vasoconstricción cerebral ${ }^{47}$.

La hipotermia posee efecto neuroprotector (reduce la liberación extracelular de glutamato, la movilización de calcio, la producción de RLO y la síntesis de óxido nítrico) y podría mejorar el pronóstico de los pacientes neurotraumatizados. Sin embargo, existen efectos secundarios que cuestionan su empleo estandarizado. Al parecer, cuando la temperatura inducida se encuentra en el rango $35-35,5^{\circ} \mathrm{C}$ sí que ha sido útil para reducir la HIC, siendo capaz al mismo tiempo de mantener una adecuada $\mathrm{PPC}^{44}$.

\section{Daño celular mediado genéticamente}

El TCE determina la expresión de muchos genes que serán los responsables 1) de la supresión de los mecanismos inhibidores de la apoptosis celular y 2) de la producción de factores neuroprotectores frente a la isquemia ${ }^{24}$.

1) Se ha documentado en estudios necrópsicos y en tejido cerebral extirpado quirúrgicamente que, a lo largo de un período postraumático que oscila entre 2 y 6 horas, el ADN nuclear aparece fragmentado, con aparente indemnidad del resto de los orgánulos celulares, lo cual sugiere que la célula está sufriendo un proceso de apoptosis. Como no existe evidencia de sistemas enzimáticos reparadores del daño apoptósico a nivel de los ácidos nucleicos en el tejido cerebral traumatizado, se considera que aquél es irreversible.

El estrés oxidativo activa la expresión de varias moléculas de señal, entre las que se encuentran las quinasas 1 y 2 (ERK 1 y 2), la quinasa proteica p38 mitógeno-activada (MAPK), o el factor de respuesta al golpe de calor (HSF1), que no son específicas del traumatismo ya que también regulan las respuestas celulares frente a otros tipos de agresión. Estas moléculas amplifican la expresión de genes diana que inducen o inhiben mecanismos de apoptosis, proliferación celular, metabolismo y crecimiento diferenciado. La caspasa 1 es una proteína proapoptósica de los mamíferos, homóloga a la codificada por el gen de muerte celular ced-3 en ciertos nematodos. La isquemia produce -por medio de una serie de moléculas de señal- superregulación de la caspasa $1 \mathrm{y}$, en consecuencia, apoptosis ${ }^{24}$. El gen ced-9 ejerce una regulación negativa sobre el ced-3. Experimentalmente, la eliminación del ced-9 condiciona la muerte celular durante el desarrollo del embrión, mientras que la pérdida del ced-3 impide la muerte celular programada normal ${ }^{19}$. Para que predomine la necrosis sobre la apoptosis celular debe existir una sobrecarga cálcica en el citoplasma mayor que dentro de la matriz mitocondrial. Cuando ocurre lo contrario, predominan los fenómenos apoptósicos.

La combinación de una droga antiapoptósica (Cicloheximida) con un antagonista NMDA (Dextrorfano) ha producido más de un $80 \%$ de reducción en el tamaño de infarto en un modelo animal de isquemia transitoria (mayor que la acción ejercida por estos agentes usados por separado). No se ha empleado, sin embargo, en la clínica humana ${ }^{22}$.

2) Unas 2 horas después del traumatismo, el cerebro expresa genes precoces (IEGs). Uno de ellos es el c-fos, necesario para la subsiguiente formación del factor de crecimiento nervioso, que posee actividad neuroprotectora. Éste defiende al cerebro contra la isquemia, en parte mediante la fosforilación que realiza sobre las ERK 1 y 2. Por otro lado, el fos/AP-1, que es un dímero (enzima cuya estructura cuaternaria activa consiste en la unión de dos polipéptidos) del fos consigo mismo, actúa regulando la respuesta al traumatismo mediante su unión con las regiones promotoras de los genes efectores neuroprotectores tardíos (que se expresan a partir de las primeras 24 horas del traumatismo). En concreto, se ha demostrado que la inhibición del fos mediante ADN antisentido aumenta el volumen del infarto secundario a un accidente cerebrovascular. Otro gen efector tardío es responsable de expresar GPDH en la periferia del foco isquémico en una cantidad 60 veces superior a su valor basal ${ }^{24}$. Esta enzima, como se sabe, está 
implicada en la reoxidación del NADH procedente de la glicolisis y de su conversión en $\mathrm{NAD}^{+}$para alimentar el ciclo de Krebs. Por lo tanto, los mecanismos por los cuales la célula escapa o no al daño oxidativo parecen depender del grado de expresión de algunos IGEs ${ }^{22}$.

\section{Evaluación del traumatismo craneoencefálico}

\section{Exploración general}

Encontrar un TCE grave aislado es improbable, por lo que interesa evaluar las posibles lesiones asociadas que puedan determinar trastornos respiratorios (contusión pulmonar, fracturas costales múltiples, broncoaspirado de sangre o vómito) y/o cardiovasculares (hipovolemia por rotura hepatoesplénica, taponamiento cardíaco, contusión miocárdica, shock medular), dada la estrecha relación que guardan con el daño cerebral secundario.

En series recientes, la asociación del TCE grave con el daño sistémico oscila entre un $25 \%$ y un $88 \%$ de los $\operatorname{casos}^{30}$. Se puede definir éste último como la presencia de $\mathrm{pO}_{2} \leq 65$ $\mathrm{mm} \mathrm{Hg}, \mathrm{pCO}_{2} \geq 45 \mathrm{~mm} \mathrm{Hg}$, tensión arterial sistólica $\leq 90$ $\mathrm{mm} \mathrm{Hg}$ y hematocrito $<30 \%$ durante las primeras horas o días después del traumatismo ${ }^{1}$.

Por otra parte, el raquis está implicado con frecuencia en los pacientes politraumatizados y, por consiguiente, una inadecuada maniobra de movilización puede desencadenar o agravar una lesión medular. Cuando existe una lesión cervical, hematomas visibles en la unión cervicotorácica o isquemia hemisférica precoz en ausencia de focos contusivos, debe descartarse la presencia de una disección carotídea, la cual -bien por fenómenos embólicos bien por efectos hemodinámicos- es la responsable de la aparición de infartos cerebrales. El doppler cervical permitirá casi siempre el diagnóstico, el cual será seguido de la restauración endovascular del calibre del vaso afecto.

\section{Examen neurológico}

En 1974 se introdujo la GCS (Tabla 1) como un procedimiento práctico de valoración del coma postraumático. Tras ser ligeramente modificada en 1977, se emplea de forma rutinaria para cuantificar el grado de reactividad neurológica con el fin de minimizar la impresión subjetiva del personal sanitario ${ }^{21}$. Asimismo, la puntuación obtenida -tras las maniobras de reanimación- constituye una importante ayuda para predecir el pronóstico final del TCE grave. Así, para una puntuación de 3 cabe esperar una tasa de $4,1 \%$ de BR y de $85 \%$ de M+EVP; para una puntuación de 4 , las tasas son $6,3 \%$ (BR) y $67 \%(\mathrm{M}+\mathrm{EVP})$; para 5 puntos, $12,2 \%$ (BR) y $47,5 \%$ (M+EVP); para 6 puntos, $29,2 \%$ (BR) y $26,5 \%$ (M+EVP); para 7 puntos, $46,6 \%$ (BR) y $18,6 \%$ (M+EVP); y para 8 puntos, $54,8 \%$ (BR) y $19 \%$
$(\mathrm{M}+\mathrm{EVP})^{11}$.

Los resultados se aplican generalmente, por convención, sobre el hemilado mejor, consignándose -por ejemplo- V2 O1 M3 (GCS =6) para el caso de un paciente que emite sonidos incomprensibles, no abre ojos e inicia una extensión con pronación interna seguida de flexión de antebrazo y del carpo (respuesta en decorticación), o bien VT O1 M3 para el mismo paciente cuando se encuentra intubado o con traqueostomía. Corresponde una puntuación de 15 a una reactividad neurológica completamente normal y una de 3 a la ausencia de respuesta neurológica.

Pueden interferir con la aplicación del GCS ciertas situaciones, como las lesiones orbitarias, la edad preverbal, aunque existe una escala adaptada para pacientes pediátricos (Tabla 2), la sedación farmacológica y las intoxicaciones entre otras ${ }^{21}$.

Independientemente de la ayuda que supone la GCS en la valoración de la gravedad del paciente con TCE, ello no exime de realizar una exploración neurológica rigurosa que permita consignar la presencia de focalidad. A este respecto, debe destacarse la información que suministra el examen de los movimientos oculares intrínsecos y extrínsecos, si bien hay que considerar que éstos puedan estar artefactados por los fármacos administrados.

\section{Valoración del estado de las pupilas}

El tamaño y asimetría pupilares sugieren a menudo la gravedad de la lesión encefálica y su localización topográfica. Los pacientes con pupilas normales tras la reanimación y durante todo el curso hospitalario presentan una tasa de M+EVP del 10\%; entre los que presentan una pupila post-reanimación anormal la tasa de M+EVP es del 47\%; entre los que sus pupilas post-reanimación son normales y después una es anormal en al menos una observación, la tasa es del $61 \%$; entre los que sus pupilas post-reanimación son normales y después ambas anormales en al menos una observación, la tasa es de 79\%; y entre los que presentan ambas pupilas post-reanimación anormales, la tasa es del $82 \%{ }^{11}$.

Las alteraciones pupilares dependen del compromiso promovido sobre el arco reflejo fotomotor en alguno de sus eslabones ${ }^{9}$, y consisten en miosis y midriasis.

- Miosis (constricción de 1-3 mm)

Tiene lugar en los estadios precoces de la herniación centroencefálica, debiéndose al compromiso de los axones simpáticos originados en el hipotálamo, lo que permite un predominio de la acción parasimpática, transmitida por el III par, y -por tanto- un tono pupiloconstrictor de base en el músculo ciliar del ojo. Prácticamente siempre, cuando es unilateral, preludia la herniación transtentorial con ulterior compresión mesencefálica y precede a la 


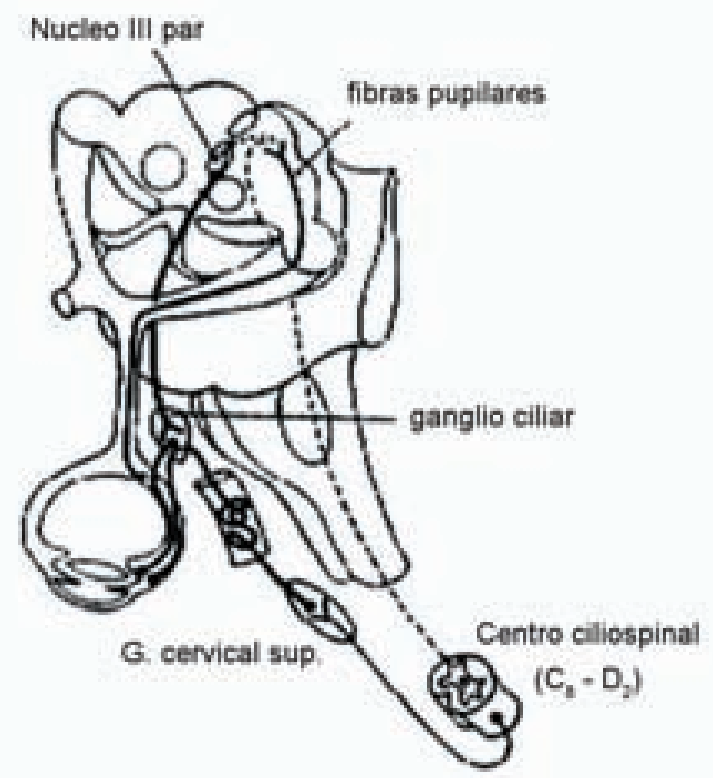

Figura 10. Esquema que representa las principales conexiones entre el músculo ciliar del ojo y las estructuras paleoencefálicas, modificado de Delmas $J$ y cols ${ }^{8}$.

midriasis paralítica.

Las lesiones pontomesencefálicas dorsales (núcleo rojo) provocan una miosis intensísima por interrupción de la señal descendente que termina en el ganglio estrellado, antes de ascender por el plexo nervioso pericarotídeo (Figura 10). Esta señal descendente actúa dilatando el músculo radial del ojo. Las lesiones bulbares pueden, por su parte, originar un síndrome de Horner más o menos completo por el mismo motivo. Si éste no se acompaña de subreactividad, será secundario a daño en el segmento cervicodorsal o en el apex pulmonar, con afectación del ganglio estrellado.

\section{- Midriasis (dilatación $\geq 6 \mathrm{~mm}$ )}

Ocurre por lesión del III par, con la secuente disfunción de sus axones parasimpáticos, lo que detiene las señales eferentes para la constricción pupilar. La causa más común es la herniación del uncus, por gradiente de presión transtentorial, el cual comprimirá al III par ipsolateral y al pedúnculo mesencefálico.

Las lesiones mesencefálicas dorsales (lámina cuadrigémina), en el origen del núcleo del III par, producen pupilas medias o débilmente dilatadas $(6 \mathrm{~mm})$, redondas o raramente discóricas, con un reflejo fotomotor débil o ausente. Tales pupilas tectales presentan en general hippus, es decir, movimientos alternantes de constricción y dilatación, asociándose a un patrón respiratorio central y son sensibles al reflejo cilioespinal (dilatación pupilar tras estímulo nociceptivo de un área ipsolateral, por ejemplo, a nivel del trapecio) puesto que la vía simpática convocada (estímulo - ganglio estrellado - plexo pericarotídeo - hipotálamo músculo ciliar) está indemne.

Las lesiones mesencefálicas ventrales (pedúnculos cerebrales), cuando son discretas, generan gran midriasis paralítica (8-9 $\mathrm{mm})$, porque no afectan a las fibras descendentes pupilodilatadoras. En general, la midriasis bilateral y fija equivale funcionalmente a una sección mesencefálica.

En ocasiones se aprecia anisocoria por traumatismo orbitario y daño asociado del nervio óptico. En esta situación, la oscilación instantánea de la luz de la linterna desde el ojo sano al desaferentado provoca una paradójica reacción pupilodilatadora en el ojo amaurótico, debiéndose al reflejo consensual que se origina en un núcleo impar mesencefálico (núcleo de Edinger-Westphal), el cual controla simultáneamente ambos núcleos-izquierdo y derecho- del III par.

\section{Valoración de los movimientos oculares extrínsecos}

\section{Centros protuberanciales}

Existe un centro pontobulbar simétrico (uno a la derecha y otro a la izquierda), en conexión con las fibras inervatorias del recto interno (III par) y con las del motor ocular lateral (VI par), cuyo estímulo 'obliga' a ambos ojos a dirigirse conjugadamente en una dirección ipsolateral al mismo en rápidos pulsos o sacadas. En el individuo normal los ojos tenderán a mantener una mirada al frente cuando se gira la cabeza a un lado u otro (reflejo oculocefálico).

En principio, la ausencia de reflejos oculocefálicos, a lo que se denomina respuesta en 'ojos de muñeca', puede indicar un trastorno de ese centro, pero como existen otras posibilidades es necesario realizar pruebas de estimulación calórica: con la cabeza del paciente a $30^{\circ}$ sobre el plano horizontal, una inyección a través del meato acústico de 20 $\mathrm{ml}$ de agua templada produce -por estimulación endolinfática- nistagmus en 20-60 segundos, siendo su componente rápido ipsilateral al oído estimulado. Con agua fría, por depresión del movimiento endolinfático, los fenómenos son inversos.

\section{Centros corticales}

También existen otros núcleos -derecho e izquierdode la mirada conjugada en los lóbulos frontales, cuya estimulación induce impulsos tónicos contralaterales en los ojos, manteniéndolos al frente en condiciones normales.

Por lo tanto:

- Una desviación conjugada de la mirada dependerá de una lesión frontal ipsilateral cuando la estimulación calórica auditiva determine respuestas fisiológicas.

- Los movimientos oculares espontáneos y erráticos, sin fijarse en ningún lugar concreto, y los cambios pupilares (uni o bilaterales) frecuentes sugerirán lesión 
truncal (i.e, difusa) contralateral al componente rápido cuando la estimulación calórica auditiva resulte negativa en ese lado.

- La abolición de reflejos oculocefálicos será debida a una lesión frontal bilateral si las respuestas a la estimulación calórica auditiva resultan normales.

- La abolición de reflejos oculocefálicos traducirá lesión bilateral del tronco o lesión cerebral difusa si la respuesta a la estimulación calórica es patológica.

\section{Neuroimagen}

La TAC es el procedimiento radiológico de elección para el diagnóstico, pronóstico ${ }^{11}$ y control evolutivo de las lesiones iniciales del TCE y de la respuesta a la terapia. Vamos a remitirnos a una clasificación que permite reconocer subgrupos de pacientes con riesgo elevado de sufrir HIC subsecuentemente ${ }^{25}$. En ella es necesario considerar 1) si el paciente está subreactivo desde el impacto (lesión difusa) y 2) si la lesión quirúrgica -tanto hiperdensa (hematoma), como hipodensa (contusión) o mixta- tiene un volumen mayor o menor de $25 \mathrm{ml}$ (lesión focal). El volumen de la lesión se calcula (en mililitros) multiplicando los tres diámetros de la lesión (en centímetros) y dividiéndolos por 2 si su morfología tiende a ser esférica, o por 3 si su morfología se asemeja a un elipsoide. De acuerdo con ello, se tienen los siguientes patrones radiológicos:

1. Lesión difusa tipo 1 (DAI 1): ausencia rigurosa de patología intracraneal visible en la TAC. Pronóstico: $\mathrm{BR}=27 \% ; \mathrm{M}+\mathrm{EVP}=17 \%$.

2. Lesión difusa tipo 2 (DAI II): las cisternas peritruncales están presentes (lo que descarta "swelling") y las estructuras de la línea media (III ventrículo) están centradas o mínimamente desplazadas $(\leq 5 \mathrm{~mm})$. En esta categoría pueden coexistir lesiones focales (i.e, pequeñas contusiones corticales aisladas, una contusión en el tronco, hemorragia subaracnoidea o múltiples petequias en el cuerpo calloso) con cuerpos extraños y fragmentos óseos de menos de 25 ml. Pronóstico: $\mathrm{BR}=8,5 \% ; \mathrm{M}+\mathrm{EVP}=25 \%$.

3. Lesión difusa tipo 3 (DAI III): la línea media está casi centrada ( $\leq 5 \mathrm{~mm}$ de desplazamiento), pero las cisternas peritruncales aparecen comprimidas o ausentes, lo que traduce la presencia de "swelling". En este grupo las lesiones focales, si existen, han de ser menores de $25 \mathrm{ml}$. Si sólo hay "swelling" el paciente es frecuentemente menor de 20 años de edad, y su PIC puede ser normal. Este perfil de lesión -al que en el apartado de 'Patología' se denominó tumefacción cerebral difusa- tiene unas connotaciones especiales, y su pronóstico depende en gran medida del GCS inicial del paciente, de la edad del mismo y de si hubo o no intervalo lúcido ${ }^{23}$. En cambio, si se asocia a lesión focal, la PIC tiende a ser progresivamente mayor, empeorando significativamente el pronóstico. La lesión focal debe ser extirpada lo más precozmente posible. Pronóstico global: $\mathrm{BR}=3,3 \% ; \mathrm{M}+\mathrm{EVP}=57 \%$.

4. Lesión difusa tipo 4 (DAI IV): desviación de la línea media $\geq 5 \mathrm{~mm}$ en ausencia de lesiones focales mayores de $25 \mathrm{ml}$. El ejemplo más típico de este perfil es el hematoma subdural agudo que se aprecia en la TAC como una fina colección subdural biconvexa y que -por su volumen tan escaso- no justifica el desproporcionado desplazamiento de la línea media. En el ejemplo propuesto, las colecciones subdurales siempre deben ser evacuadas lo más precozmente posible, pues la presencia de las mismas constituye un factor de riesgo para el incremento del daño secundario. Pronóstico: $\mathrm{BR}=3,1 \%$; $\mathrm{M}+\mathrm{EVP}=75 \%$.

5. Lesión focal no evacuada: existen focos quirúrgicos $\geq 25 \mathrm{ml}$. El desplazamiento de la línea media es proporcional al volumen del foco, y la puntuación en la GCS está, asimismo, relacionado directamente con el grado de desplazamiento. Si se desarrolla daño cerebral secundario, pueden tender a crecer, rodearse de edema vasogénico y generar HIC.

Como ejemplos representativos están los hematomas epidurales puros y las contusiones puras. Los hematomas epidurales deben ser considerados quirúrgicos siempre que su volumen supere los $25 \mathrm{ml}$. Si se evacuan en menos de 4 horas después del impacto tienen buen pronóstico. $\mathrm{Si}$, por el contrario, la cirugía se demora se pueden convertir en un patrón de lesión difusa tipo 4. Las contusiones únicas puras, con frecuencia, no determinan aumentos patológicos de la PIC por lo que pueden tratarse conservadoramente. Cuando se asocia daño cerebral secundario, habrá HIC y el pronóstico también será malo, por lo que deberán ser extirpadas. En otras ocasiones, habrá contusiones múltiples unilaterales que generan un gran desplazamiento de la línea media e HIC. Pronóstico: $\mathrm{BR}=2,8 \%$; $\mathrm{M}+\mathrm{EVP}=69,5 \%$.

El pronóstico de las contusiones múltiples puede mejorar con la cirugía, por lo que los focos más voluminosos deberán ser intervenidos quirúrgicamente. Por otro lado, pueden encontrarse pacientes con lesiones focales múltiples bihemisféricas. Éstas también elevan la PIC, pero posiblemente su tasa de mortalidad sea sensiblemente inferior a la de las contusiones múltiples unilaterales, lo cual quizá dependa del escaso desplazamiento de la línea media y, por consiguiente, del retardo en producirse el enclavamiento ${ }^{23}$. El mantenimiento centrado de la línea media dependería del efecto de contrabalanceo generado por gradientes de presión análogos en ambos hemisferios. No obstante, si no se adopta una actitud quirúrgica agresiva, tendrá lugar una HIC incontrolable.

6. Lesión focal evacuada: alude a cualquier lesión extirpada quirúrgicamente. Dentro de este patrón postoperatorio pueden encontrarse dos situaciones especiales: 1) clara mejoría de los parámetros radiológicos, y 2) presencia de "swelling" asociado o no a nuevas lesiones focales. A este 
respecto, cabe mencionar el hematoma subdural o epidural que preoperatoriamente generaba un desplazamiento proporcional de la línea media. Postoperatoriamente, bien por demora en la cirugía, bien por algún episodio de hipotensión, puede apreciarse en la TAC de control un "swelling" hemisférico (lesión difusa tipo 4). Pronóstico: $\mathrm{BR}=5,1 \% ; \mathrm{M}+\mathrm{EVP}=51 \%$.

Dado que el $53 \%$ de los pacientes graves mantienen un mismo patrón de TAC, el 26\% lo mejoran y el 20\% lo empeoran, es muy conveniente -sobre todo si el estudio TAC se ha realizado de forma precoz (a menos de 3 horas del traumatismo)- realizar un control radiológico dentro de las siguientes 12 horas $^{23}$.

\section{Monitorización de la presión intracraneal}

La monitorización de la PIC permite adelantarse al deterioro neurológico y controlar la efectividad de las medidas terapéuticas empleadas. Los sistemas más utilizados son los transductores acoplados a fluidos (catéter intraventricular) y los sensores intraparenquimatosos. La ventaja de los primeros radica en el hecho de que posibilitan la evacuación de LCR en caso de HIC y la de los segundos en que siempre permitirán una lectura de las cifras de PIC aún cuando los ventrículos -por estar a veces muy disminuidos de tamañosean difíciles de canular. La implantación del sensor deberá realizarse en el hemisferio con mayor volumen lesional debido a la existencia de los gradientes transcorpantimentales de presión mencionados anteriormente ${ }^{28}$.

Las guías clínicas recomiendan que sean monitorizados 1) todos los pacientes con TCE grave y TAC patológico, y 2) los pacientes con TCE grave y TAC normal que reúnan dos o más de las siguientes características: edad superior a los 40 años, respuestas motoras francamente anormales $(\mathrm{M} \leq 4) \mathrm{y}$ caídas de tensión arterial por debajo de $90 \mathrm{~mm} \mathrm{Hg}$ en algún momento de su evolución ${ }^{28}$. La lectura continua del trazado de PIC en papel o monitor permite apreciar las variaciones de este parámetro y aplicar las medidas apropiadas para reducir la HIC sin detrimento de la presión de perfusión cerebral ${ }^{5,46}$.

Idealmente, constatar que la complianza está disminuyendo antes de que la PIC ascienda permitirá adelantarse a los problemas derivados de la HIC. Para ello, es útil examinar el denominado índice presión-volumen (PVI) que se puede calcular observando el descenso que se produce en la PIC desde su valor basal $\left(\mathrm{P}_{0}\right)$ hasta una magnitud $\left(\mathrm{P}_{\mathrm{m}}\right)$ que resulta tras evacuar -a través de la cánula ventricular- un volumen (V) de LCR igual a $2 \mathrm{ml}$ en 1 segundo ${ }^{3,6,26}$.

Los parámetros mencionados se introducen en la siguiente función:

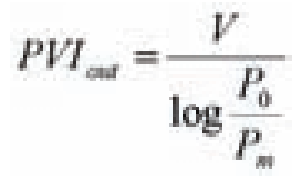

siendo $25 \mathrm{ml}$ el valor normal del PVI en los humanos.

Los pacientes con TCE que inicialmente presentan un PVI $\geq 20 \mathrm{ml}$ y no desarrollan ulteriormente nuevas lesiones intracraneales, no experimentarán en general HIC o, en todo caso, las elevaciones esporádicas de la PIC serán fácilmente yugulables. Los pacientes con PVI menor de $20 \mathrm{ml}$ desarrollan casi siempre HIC para cuyo control se precisan importantes esfuerzos terapéuticos.

Una vez controlada la HIC, deberían obtenerse valores estables de PVI mayores de $20 \mathrm{ml}$ durante 3-4 días antes de optar por retirar la cánula pues, en caso contrario, podrían aparecer nuevos brotes de HIC y pasar desapercibidos.

El espacio subaracnoideo espinal contribuye en un $38 \%$ al PVI total, por lo que la existencia de un bloqueo craneoespinal secundario a una lesión cervical traumática invalida las consideraciones precedentes ${ }^{25}$. El PVI, al no estar influenciado por las variaciones de la $\mathrm{pCO}_{2}$, no tiene utilidad para estimar el tono vasomotor ni el grado de dilatación de las arteriolas cerebrales ${ }^{6}$.

Se ha sugerido también que un aumento progresivo de la amplitud del pulso de PIC, hasta 50-60 mm Hg, podría deberse tanto a agotamiento de la complianza como a cambios en la hemodinámica cerebral. Sin embargo, estas apreciaciones valorativas resultan inútiles en la práctica clínica $^{18}$.

Por otra parte, debe tomarse en consideración el hecho de que la onda de pulso de PIC (que se aprecia bien en el trazado a una velocidad de $\left.10 \mathrm{~mm} . \mathrm{s}^{-1}\right)$ está formada normalmente por tres picos o armónicos llamados, de más precoz a más tardío, $\mathrm{P}_{1}, \mathrm{P}_{2}$ y $\mathrm{P}_{3}$. Los dos primeros están relacionados con la hemodinámica arterial, y el último con la venosa (Figura $7 \mathrm{~A}$ ).

Cuando la onda normal se transforma en otra de morfología redondeada, probablemente se está produciendo vasodilatación (hiperemia), que sugiere un deterioro progresivo de la autorregulación y parálisis arteriolar (Figura 7 B). Este fenómeno se ha observado aún cuando las cifras de PIC son reducidas, por lo que la supresión de los armónicos en el registro continuo es independiente del estado de complianza que posea el sistema craneoespinal. Por ello, el análisis de la morfología de esta onda ofrece información útil sobre la existencia de vasodilatación cerebral ${ }^{18}$.

\section{Monitorización de la hemodinámica y metabolismo cere- brales}

La importancia de la isquemia y la elevada prevalencia de alteraciones en los mecanismos de control autorregulatorio cerebrovascular determinan la necesidad de evaluar -en ocasiones- algunos parámetros básicos indicadores del FSC y del metabolismo cerebral en el TCE grave.

Los procedimientos más frecuentemente empleados a tal efecto son los siguientes: 


\section{Oximetría yugular}

Se determina mediante lectura continua con sistemas de fibra óptica en una arteria periférica y en el golfo de la yugular interna correspondiente al seno transverso dominante, que contiene sangre no mezclada con la que proviene de tejidos extracerebrales.

El seno dominante es a veces difícil de determinar, pero mediante doppler yugular o, si existe un transductor parenquimatoso insertado, puede lograrse su identificación mediante el test de oclusión yugular de Andrews. El FSC puede calcularse de acuerdo con la notación siguiente:

$$
F S C=\frac{\mathrm{CMRO}_{2}}{\left[\mathrm{SaO}_{2}-\mathrm{SjO}_{2}\right]}
$$

donde $\mathrm{SaO}_{2}$ es la saturación arterial de oxígeno y $\mathrm{SjO}_{2}$ la saturación yugular de oxígeno. La diferencia entre ambas se conoce como extracción cerebral de oxígeno $\left(\mathrm{CEO}_{2}\right)$. De este modo, cuando el FSC aumenta, la $\mathrm{CEO}_{2}$ se reduce y viceversa. El rango normal de este parámetro está entre $24 \%$ y $40 \%$. Los valores dentro de estos límites indican un acoplamiento correcto metabolismo/flujo, los valores inferiores a $24 \%$ sugieren hipervascularización cerebral global (hiperemia, "swelling"), y los valores superiores a $40 \%$ traducen la existencia de hipoperfusión ${ }^{8}$. Sin embargo, para obtener un reflejo proporcional de los cambios de FSC se suele emplear únicamente la determinación continua de $\mathrm{SjO}^{2}$, siempre y cuando se asuma que $\mathrm{SaO}_{2}$ y $\mathrm{CMRO}_{2}$ son constantes.

Se considera que el valor normal de $\mathrm{SjO}_{2}$ está entre $55 \%$ y $71 \%$ y que los valores de $50 \%$ mantenidos durante 10 minutos indican isquemia grave. Por ello, el objetivo del control metabólico debería ser el mantenimiento de $\mathrm{SjO}_{2}$ por encima de 55\%. De acuerdo con la notación previa, si $\mathrm{SjO}_{2}$ es igual o menor a 54\% se está produciendo hipoperfusión (aumenta el denominador y -por tanto- también el FSC). Si es superior a $75 \%$ probablemente hay hiperemia (disminuye el denominador y -consiguientemente- aumenta el FSC) ${ }^{8}$. No obstante también podría añadirse una reducción del $\mathrm{CMRO}_{2}$ dado que este índice no tiene porqué ser constante. De hecho puede disminuir, por ejemplo, por disfunción de la mitocondria o por depresión metabólica secundaria al empleo de barbituratos. En tal situación, a pesar de que los valores de $\mathrm{SjO}_{2}$ sean altos, podrían tener lugar fenómenos isquémicos. Por tanto, la determinación aislada de los valores de saturación venosa no permite en ciertas circunstancias distinguir entre hiperemia e infarto. La mejor manera de resolver esta duda (aunque de forma incompleta, como se verá más adelante) es calcular la producción cerebral de lactato, lo cual puede estimarse mediante la determinación del índice lactato/oxígeno (LOI)

$$
L O I=-\frac{A V D L}{A V D O_{2}}
$$

siendo AVDL la diferencia arterioyugular de lactato y $\mathrm{AVDO}_{2}$ la diferencia arterioyugular de oxígeno. El signo menos se utiliza aquí para que el valor de la fracción sea positivo ya que AVDL va a ser siempre negativo puesto que existe más lactato en la sangre venosa que en la arterial. El valor normal de LOI es menor de $0,03 \mathrm{y}$, cuando alcanza el límite de 0,08 , indica que se está generando un estado de isquemia o infarto cerebral puesto que la excesiva producción de lactato revela que la glucosa se está metabolizando por vía anaeróbica ${ }^{34}$.

La oximetría yugular es un procedimiento invasivo no exento de complicaciones, como la trombosis de un seno venoso que, aunque poco frecuentes, pueden condicionar el pronóstico del paciente. Asimismo, las medidas que se obtienen no siempre son fiables, por lo que hay que recalibrar el sensor con frecuencia.

\section{Otros procedimientos}

La espectroscopía por infrarrojos es un método no invasivo, de aplicación muy sencilla, para determinar el FSC. Sus mayores inconvenientes son que estudia una zona limitada ( $40 \mathrm{~mm}$ de profundidad), que cualquier interposición (i.e., hematoma subdural, contusión) invalida sus resultados y que hay escasa información para interpretar su adecuada correlación con la $\mathrm{SjO}_{2}$ y otros parámetros fisiológicos. Hay también estudios en los que, curiosamente, con esta técnica se obtuvieron valores similares de oximetría regional tanto en cadáveres e individuos con muerte cerebral como en voluntarios sanos ${ }^{31}$.

El doppler transcraneal no permite en ocasiones diferenciar entre fenómenos tan opuestos como el vasoespasmo y la hiperemia dado que este procedimiento no es capaz de establecer el estado de la microcirculación cerebral, la cual es responsable de la vascularización adecuada del parénquima. Por otra parte, la eficiencia de la circulación no puede inferirse a partir de lecturas de valor absoluto de velocidad sobre vasos de calibre relativamente grande (arteria silviana). Asimismo, el valor absoluto de la velocidad de flujo puede variar según la edad, sexo, hematocrito, $\mathrm{pCO}_{2}$, actividad metabólica cerebral, gasto cardíaco y otras variables.

En la microdiálisis cerebral se colocan uno o más catéteres en el espacio extracelular del parénquima (tejido sano y/o área de penumbra) y se contrasta la información con otro catéter colocado en el tejido subcutáneo. Los catéteres tienen una membrana semipermeable a través de la que se intercambian solutos, a favor de un gradiente de concentración, entre la solución infundida y el LCR. Cada catéter lleva incorporada una bomba de infusión 
continua que perfunde volumen de solución a $0,3 \mu \mathrm{L} \cdot \mathrm{min}^{-1}$. Se intercambian los solutos a través de la membrana semipermeable en la punta del catéter, y un equipo analizador informatizado analiza los cambios producidos en la composición de la solución inicial. Las variables químicas de particular interés durante los cuidados críticos son las relacionadas con la glicolisis (glucosa, piruvato y lactato), la degradación de las membranas celulares (glicerol) y el transporte sináptico (GABA, glutamato, aspartato). La mayor ventaja práctica que ofrece su empleo reside en el hecho de que cuando se obtiene un aumento de piruvato, asociado a un LOI normal, indica una situación hipermetabólica, mientras que cuando se obtiene elevación de lactato, asociado a un incremento de dicho índice, sugiere isquemia. Su limitación más importante es que monitoriza un área muy localizada ${ }^{31}$.

Existe la posibilidad de examinar de forma invasiva -mediante un microelectrodo de Clark en el extremo de un catéter- la presión parcial de oxígeno tisular $\left(\mathrm{PtiO}_{2}\right)$ y con ello el grado de oxigenación cerebral. El catéter se coloca en el tejido cerebral a una profundidad subdural entre 22 y $27 \mathrm{~mm}$. Aunque no hay unanimidad acerca de qué región es la óptima, existe mayor consenso en la implantación del electrodo en una zona frontal en caso de patología difusa, y que en caso de patología local el médico elija la región que considere más relevante en lo que se refiere a la hipoxia. Los valores descritos como normales en la sustancia gris cortical oscilan entre 24 y $45 \mathrm{~mm}$ de $\mathrm{Hg}$ y en la sustancia blanca frontal se consideran compatibles con isquemia cifras por debajo de $15 \mathrm{~mm} \mathrm{Hg}$. Valores de $\mathrm{PtiO}_{2}>20$ $\mathrm{mm} \mathrm{Hg}$ tienden a correlacionarse con buen pronóstico. Dado que la $\mathrm{PtiO}_{2}$ es directamente proporcional al FSC e inversamente proporcional al $\mathrm{CMRO}_{2}$, proporciona información del mínimo valor de PPC necesario para mantener una oxigenación cerebral adecuada ${ }^{29,31,51}$. Sin embargo, el que la $\mathrm{PtiO}_{2}$ se mantenga normal no implica necesariamente que el metabolismo cerebral aerobio sea correcto: un posible fallo mitocondrial en el contexto del TCE puede impedir que la oxidación de la glucosa se verifique con normalidad ${ }^{31}$.

Dadas las consideraciones previas, cabe concluir que la información que aporta aisladamente cualquiera de los procedimientos mencionados no es suficiente para manejar correctamente al paciente con TCE grave. Por el contrario, deberían aplicarse los suficientes métodos que aporten información valiosa, y obviar aquellos que sean redundantes y fuente de yatrogenia.

\section{Tratamiento}

\section{En el lugar del accidente}

El control de los orígenes potenciales del daño secun- dario cobra en esta fase un interés especial: obliterar las fuentes obvias de hemorragia, eliminar los obstáculos en el tracto respiratorio alto, manejar eficazmente la hipotensión (prestando atención a la causa -hipovolémica o medular- de ésta, pues el tratamiento es radicalmente distinto), disminuir el dolor, y aportar oxígeno cuando se sospeche daño sistémico.

\section{En el transporte}

Excepto cuando se precise reanimación cardiopulmonar y ésta no pueda realizarse en la escena del accidente, el paciente crítico (i.e, TCE grave y moderado, y TCE leve con politraumatismo) debería ser transferido a un centro de tercer nivel dado que muchos insultos secundarios tienen lugar en los traslados de un hospital a otro. Será colocado en posición neutra supina, con collar cervical, controlándose perfectamente la vía aérea, de modo que el eventual vómito pueda ser aspirado mediante un sistema de vacío.

\section{En la sala de urgencias}

Se evaluarán los parámetros sistémicos, neurológicos y radiológicos mencionados anteriormente. Todos los pacientes con TCE grave o moderado se explorarán mediante TAC cerebral y serán ingresados para observación y tratamiento. En lo concerniente a pacientes con TCE leve cabe hacer dos distinciones:

1) El paciente podrá ser dado de alta con instrucciones específicas acerca de la vigilancia neurológica domiciliaria, que se efectuará durante 48 horas, si no posee ninguna de las siguientes características: disminución postraumática del nivel de conciencia, cefalea significativa, amnesia peritraumática o focalidad neurológica, fractura craneal, sospecha de intoxicación, factores de riesgo (edad $\geq 70$ años, anticoagulación, hepatopatía, accidentes cerebrovasculares y/o TCE previos), vive solo y/o muy distante del centro hospitalario y el nivel intelectual de los encargados de vigilarle es inapropiado. En esta categoría la tasa de morbimortalidad es del $0 \%$.

2) Si presenta alguno de los rasgos anteriormente citados, se debería realizar un TAC cerebral y dejarle ingresado para observación durante 48 horas. En este grupo la tasa de morbi-mortalidad puede llegar a situarse en torno al $1 \%$.

\section{En la sala de neurocirugía}

En principio, los pacientes que han sufrido un TCE moderado o leve, sin daño sistémico asociado, podrán ser manejados en planta. Se debería realizar una TAC de control a las 12-24 horas de su admisión, y son potencialmente subsidiarios de las medidas de vigilancia, control y 
tratamiento que se deduzcan como aplicables del apartado siguiente.

\section{En la unidad de cuidados intensivos}

Lo que sigue a continuación incluye a los pacientes con GCS $\leq 8$ y a aquéllos, en otras categorías, que se deterioran. En todas las fases del programa terapéutico que se propone, debe considerarse la posibilidad de cirugía si los parámetros fisiológicos y radiológicos así lo aconsejan.

1. Control de la hipoxia cerebral: como estrategia habitual, todo paciente con TCE grave o con un GCS $>8$ pero que acarrea daño sistémico será sometido a relajación, intubación y ventilación mecánica como mínimo durante 24 horas. En ausencia de HIC está formalmente desaconsejado el empleo de hiperventilación para evitar los efectos de la isquemia provocados por la vasoconstricción que promovería la hipocapnia. El uso de calcioantagonistas (dihidropiridina de nimodipino) podría ser aconsejable para evitar el angioespasmo en la hemorragia subaracnoidea postraumática ${ }^{42,45}$.

2. Control de la complianza: el objetivo inicial es oponerse a que la complianza craneoespinal se agote. Existen algunos principios simples que han demostrado su eficacia en este sentido: 1) Impedir retenciones gratuitas de fluido intracraneal facilitando el retorno venoso con la cabeza del paciente a $20^{\circ}$ sobre el plano horizontal; 2) Evitar ataduras del tubo orotraqueal alrededor del cuello; y 3) Limitar el empleo de la presión espiratoria final positiva a la estricta indicación de cortocircuito pulmonar y, en todo caso, dentro del rango de $5-10 \mathrm{~cm}$ $\mathrm{H}_{2} \mathrm{O}^{28}$.

3. Tratamiento del edema: estudios prospectivos con asignación aleatoria no han demostrado ninguna ventaja en el empleo de dexametasona y sí, en cambio, la aparición de efectos colaterales adversos (i.e, hemorragia digestiva, hiperglucemia, trombosis cerebral vascular, inmunosu-presión). Por otro lado, la contribución relativa del edema citotóxico y del edema vasogénico en los diferentes tipos de TCE es desconocida. Por ello parece razonable restringir su uso a las contusiones cerebrales. No debe tampoco olvidarse la existencia de dos tipos especiales de edema celular que se asocian con: 1) el síndrome de secreción inadecuada de hormona antidiurética (SIADH) y 2) el síndrome de depleción salina cerebral (CSW).

1) El SIADH es un estado normovolémico ( $\mathrm{PVC}=6-10$ $\mathrm{cm} \mathrm{H}_{2} \mathrm{O}$ ó 4,4-7,3 $\mathrm{mm} \mathrm{Hg}$ ) o hipervolémico (PVC $>11 \mathrm{~cm} \mathrm{H}_{2} \mathrm{O}$ ó $8 \mathrm{~mm} \mathrm{Hg}$ ) que se presenta a veces hacia el segundo o tercer día del impacto. Parece ser debido a una excesiva liberación de $\mathrm{ADH}$, bien por recalibración de los osmorreceptores hipotalámicos a un umbral más bajo que el fisiológico, bien por producirse una fuga constante de ADH no ajustable por los valores de la osmolaridad ${ }^{35}$. Los criterios diagnósticos son: hiponatremia dilucional $\left([\mathrm{Na}]<135 \mathrm{mEq} \cdot \mathrm{L}^{-1}\right)$, osmolaridad urinaria mayor que la plasmática, funciones tiroidea, adrenal y renal normales, y ausencia de edema periférico o deshidratación. Estos criterios no sirven en presencia de dolor intenso, náuseas, empleo de diuréticos, o hipotensión pues estos factores estimulan la secreción de ADH incluso en presencia de hipotonicidad plasmática. El tratamiento es controvertido pero básicamente pueden seguirse los siguientes pasos: a) Restricción hídrica (500 a $1.200 \mathrm{ml} / 24$ h de suero salino); b) Cuando, a pesar de este régimen, no se logra normalizar la natremia en 72 horas o hay deterioro neurológico sin correlación radiológica u oximétrica, se puede proceder con una perfusión de $0,5 \mathrm{ml} / \mathrm{Kg} / \mathrm{h}$ de suero salino al $0,9 \%$ (que contiene $154 \mathrm{mEq} \cdot \mathrm{L}^{-1}$ ) si la natremia es mayor de $125 \mathrm{mEq} . \mathrm{L}^{-1}$ o de suero salino al 3\% si la natremia es menor de $125 \mathrm{mEq} \cdot \mathrm{L}^{-1}$. Esto supone un ingreso aproximado de sodio de $5,4 \mathrm{mEq} / \mathrm{h}$ en el primer caso, y de $18,5 \mathrm{mEq} / \mathrm{h}$ en el segundo. Algunos centros establecen como límite al incremento diario de sodio plasmático la cifra de $25 \mathrm{mEq} \cdot \mathrm{L}^{-1}$. No obstante, si la hiponatremia es peligrosa, también lo es su corrección rápida porque puede determinar un cuadro de desmielinización osmótica (i.e, mielinosis central pontina $)^{49}$. Por ello, en rigor, no pueden recomendarse incrementos de $\left[\mathrm{Na}^{+}\right]$plasmático a una tasa superior a $12 \mathrm{mEq} . \mathrm{L}^{-1}$ por día ${ }^{35}$.

2) $\mathrm{El} \mathrm{CSW}$ es un estado hipovolémico ( $\mathrm{PVC}=0-5 \mathrm{~cm}$ $\mathrm{H}_{2} \mathrm{O}$ ó 0-3,6 mm $\mathrm{Hg}$ ) o normovolémico secundario a incapacidad renal para reabsorber sodio, que determina pérdida progresiva de sal y depleción de volumen. Los mecanismos implicados en este síndrome no se conocen, pero la hipótesis más difundida asume que determinadas lesiones cerebrales estimulan un circuito hipotalámico que promueve excesiva liberación de péptidos natriuréticos tanto en la aurícula como en el miocardio. La importancia de un diagnóstico diferencial correcto radica en el hecho de que la restricción hídrica como modus operandi conduce en el CSW a hemoconcentración, aumento de la viscosidad hemática, reducción de la perfusión cerebral y, finalmente, a isquemia-infarto ${ }^{17}$. Los criterios diagnósticos son los mismos que en el SIADH, con la salvedad de que no hay hipervolemia y de que existe anemia (Ho $\leq 27 \%$ ). El tratamiento puede consistir en la siguiente pauta: a) Reposición de fluido con $50 \mathrm{ml} / \mathrm{Kg} /$ día (si existe hipovolemia, $60 \mathrm{ml} / \mathrm{Kg} /$ día aproximadamente); b) Transfusión de sangre entera; y c) Administración 
de $12 \mathrm{~g} / 24 \mathrm{~h}$ de sal por sonda nasogástrica o de 400 $\mathrm{ml}$ de suero salino al 3\% intravenosamente (este volumen debe formar parte de los ingresos diarios totales de fluido). $\mathrm{Si}$ a las 72 horas no se han conseguido dos lecturas de sodio plasmático consecutivas, y separadas por 12 horas, de al menos $130 \mathrm{mEq} \cdot \mathrm{L}^{-1}$, es necesario asegurarse de que efectivamente hay una reducción del volumen sanguíneo $(<65 \mathrm{ml} / \mathrm{Kg})$, lo cual puede verificarse con la inyección de un volumen conocido de hematíes autólogos marcados con $\mathrm{Cr}^{51}$. Si se confirma la contracción del volumen sanguíneo, se continuará con la misma pauta otras 48 horas. Si, por el contrario, el volumen sanguíneo resulta ser superior a $75 \mathrm{ml} / \mathrm{Kg}$ se actuará, como en el SIADH, restringiendo el aporte de fluido ${ }^{7,17}$.

4. Control de la hipertensión intracraneal: una vez agotada la complianza, la PIC comienza a ascender, lo cual constituye el factor más importante en la reducción del FSC y en la generación de movimientos de masa intracraneal. Sin embargo, hay que reconocer que -si uno de los objetivos perseguidos es mantener la PPC por encima de $70 \mathrm{~mm} \mathrm{Hg}$ - se debe estar dispuesto a afrontar en ocasiones la futilidad de todos los esfuerzos para controlar la HIC. El manejo de ésta puede realizarse en este orden ${ }^{5,46}$ :

$1^{\circ}$. Drenaje ventricular de $L C R$ : la evacuación repetida de 2-3 ml de LCR a través del catéter de la ventriculostomía produce inicialmente buenos resultados, aunque la manipulación o mantenimiento de aquél por más de 4-5 días se asocia a una elevada tasa de infección. Usualmente esta maniobra llega muy pronto a ser inútil para controlar la HIC.

$2^{\circ}$. Deshidratación: el agente más empleado es el manitolal $20 \%$ (dosis rápidas de $0,25-1 \mathrm{mg} / \mathrm{Kg}$ ), tantas veces como resulten eficaces, teniendo en cuenta lo siguiente: a) la presión venosa central no debe bajar de $5 \mathrm{~cm} \mathrm{deH}_{2} \mathrm{O}$ y la osmolaridad plasmática debe mantenerse en 310-320 mOsm. $L^{-1}$; b) el empleo de este diuréticoosmótico por más de 7 días o los estados hiperosmolares conducen a la incorporación del agente a la célula con aumento secuente de la PIC, a acidosis metabólica y a insuficiencia renal aguda; c) es muy importante mantener la normovolemia con albúmina, cristaloides osangre, pues sólo interesa 'secar' el cerebro; y d) si el manitol falla o la osmolaridad sérica asciende $25 \mathrm{mOsm} . \mathrm{L}^{-1}$ por encima del nivel normal, el diurético de elección es la furosemida.

$3^{\circ}$. Hiperventilación: cuando las medidas que anteceden llegan a ser ineficaces, se inducirá hiperventilación, manteniendo la $\mathrm{pCO}_{2}$ en $30-35 \mathrm{~mm} \mathrm{Hg}$. Cifras inferiores son peligrosas porque casi con certeza producen isquemia debido tanto al efecto vasoconstrictor de la hipocarbia como al desplazamiento hacia la izquierda que la alcalosis tisular determina sobre la curva de disociación de la hemoglobina (efecto Bohr). Como terapia de segundo nivel, en caso de HIC refractaria, después de las primeras 24 horas del traumatismo y en ausencia de isquemia global comprobada por oximetría, puede emplearse hiperventilación agresiva de forma aislada, manteniendo la $\mathrm{pCO}_{2}$ en $27 \pm 2 \mathrm{~mm} \mathrm{Hg}$.

$4^{\circ}$. Coma farmacológico: todavía, si los procedimientos anteriores fallan, se puede emplear -asimismo como terapia de segundo nivel- pentobarbital sódico en dosis de carga de $10 \mathrm{mg} / \mathrm{Kg}$ en 30 minutos y $5 \mathrm{mg} / \mathrm{Kg}$ cada hora durante 3 horas, seguido de una dosis de mantenimiento de $1 \mathrm{mg} / \mathrm{Kg} / \mathrm{h}$. Es de extremada importancia evitar los episodios de hipotensión que pueden ser desencadenados por el barbiturato ${ }^{10}$. Alternativamente, puede utilizarse una dosis de carga de propofol $(1 \mathrm{mg} /$ $\mathrm{Kg}$ ) durante 10 minutos, seguida de una infusión que comienza con incrementos de $100 \mu \mathrm{g} / \mathrm{Kg} / \mathrm{min}$ cada 5 minutos, hasta que se consiga una supresión de puntas en el EEG en períodos de 4-8 segundos, manteniendo este patrón 5 minutos. Es de la mayor importancia decidir juiciosamente en cada caso si se emplea o no esta terapia de segundo nivel, pues siempre produce hipotensión, vasoconstricción (o quizá vasoplejia cerebral), y depresión de la actividad de los linfocitos T.

$5^{\circ}$. Craniectomía descompresiva: en pacientes que experimentan HIC mayor de $30 \mathrm{~mm}$ Hg durante más de 15 minutos, refractaria a las medidas precedentes y excluyendo aquellos casos con lesiones bilaterales o con midriasis bilateral paralítica, se han practicado amplias craniectomías sobre ambas regiones frontotemporoparieto-occipitales y duroplastia. Se ha sugerido, asimismo, que es más importante en el efecto beneficioso sobre el pronóstico la cantidad de hueso extirpado en la base temporal que el tamaño total de la craniectomía. El único estudio prospectivo de este tipo de tratamiento, realizado en 13 pacientes pediátricos y 14 controles, demostró que la HIC se redujo y que el pronóstico funcional era mejor en el grupo de los pacientes con craniectomías, aunque no de forma estadísticamente significativa. Las complicaciones descritas con esta técnica consisten en elevada incidencia de hematomas intracraneales y de hidrocefalia ${ }^{4}$.

5. Control metabólico: a efectos prácticos, éste se dirige a suprimir la acidosis metabólica, los estados hiperglucémicos secundarios a diabetes, fiebre, sepsis y crisis comiciales, puesto que incrementan el $\mathrm{CMRO}_{2}$ $\mathrm{y}$, por tanto, reducen el estrecho margen que permite disminuir el FSC (entiéndase PPC) y, secundariamente, la PIC. En un contexto hipometabólico ideal también sería deseable una nutrición de baja energía para no 
convocar indirectamente vías anaeróbicas, pero esto casi nunca será posible dada la alta prevalencia de complicaciones generales en el TCE. En lo que concierne a la epilepsia, ha existido una tendencia a considerar que la prevención de las crisis comiciales precoces (en la primera semana del traumatismo) contribuiría a impedir el desarrollo de epilepsia postraumática. Sin embargo, muchos estudios clínicos han demostrado que la profilaxis anticomicial reduce la incidencia de las crisis precoces pero no modifica la de las tardías ${ }^{50}$. Así pues, la profilaxis no debería emplearse más que durante los 7-10 días siguientes al TCE, y discontinuarla después. Si ulteriormente aparecen crisis, deberían tratarse como si fuesen ataques de comienzo reciente. Finalmente, frente a la HIC refractaria, y antes de proceder con las terapias de segundo nivel, se recomienda el empleo de hipotermia moderada $\left(35-35,5^{\circ} \mathrm{C}\right)$ y la aplicación de métodos invasivos para el control metabólico, básicamente la monitorización de la $\mathrm{SjO}_{2}$ y del LOI. La hipotermia por debajo de la temperatura reseñada se asocia a inmunosupresión, hipopotasemia (con intensa hiperpotasemia en el período de recalentamiento que puede determinar una parada cardíaca) y trastornos graves de la coagulación. Como terapia experimental, podría ser aconsejable añadir vitamina E (400 U/día por vía intravenosa ó $1000 \mathrm{U}$ cada 8 horas por sonda nasogástrica) y vitamina $\mathrm{C}$ (1 g en $100 \mathrm{ml}$ de suero con dextrosa al 5\% cada 8 horas).

$\underline{\text { En la unidad de rehabilitación }}$

El sistema nervioso no es estático. El hecho de que podamos aprender, modificar nuestro comportamiento, adaptarnos a nuevos situaciones y recobrar la función después de un traumatismo constituyeron indicadores de que existía una plasticidad neuronal. Existe una neuroplasticidad a corto plazo (dolor por desaferentación, miembro fantasma doloroso transitorio). Asimismo la plasticidad tiene importancia a largo plazo, como se ha demostrado mediante una serie de observaciones en primates que habían sufrido extensas rizotomías cervicales. El análisis de los mapas corticales de esos monos reveló que el área facial adyacente se había extendido -y mantenido meses después- a las áreas de la extremidad superior denervada, lo cual se relacionaba con disminución en los niveles de receptores inhibitorios y aumento de la transmisión excitatoria, particularmente la relacionada con los receptores NMDA tanto corticales como subcorticales. Este tipo de neuroplasticidad recuerda al refuerzo de la eficiencia sináptica uso dependiente, que constituye una de las bases de la teoría del aprendizaje: los citados mecanismos parecen importantes en el desarrollo inicial del sistema nervioso, en el cual el uso conduce al refuerzo sináptico y el desuso a la desaparición de las sinapsis en desarrollo. Esta hipótesis se ve reforzada por un estudio realizado con primates a los que se les enseñó a utilizar varios dedos en una tarea de percepción cutánea. A medida que los animales progresaban en su aprendizaje, la representación cortical de los dedos en cuestión se expandía ${ }^{19}$.

La neuroplasticidad a largo plazo no es solamente una propiedad del cerebro normal sino que también existe en individuos que han sufrido un ictus. Posiblemente la liberación de noradrenalina en exceso es crítica para que se establezcan nuevas sinapsis después de un accidente cerebrovascular. Así, varios estudios han demostrado que la d-anfetamina (cuyo efecto es la liberación presináptica de aquel neurotransmisor), en conjunción con la fisioterapia, aceleran la recuperación motora tanto en gatos hemipléjicos -a raíz de una ablación frontal- como en humanos que han sufrido un episodio isquémico grave en la región de la arteria silviana. Un estudio prospectivo con asignación aleatoria en el que se rehabilitaba a un grupo pacientes ictales demostró un aumento significativo en la velocidad y grado de recuperación en el grupo que había recibido 10 $\mathrm{mg}$ de dexedrina cada 4 días frente al grupo con placebo ${ }^{19}$.

\section{Bibliografía}

1. American College of Surgeons. Committe on trauma. Resources for Optimal Care of the Injuried Patients. Chicago: ACS, 1990.

2. Asgeirsson, B., Grände, P.O., Nordström, C.H.: Tratamiento del edema cerebral postraumático con especial referencia al protocolo de Lund, en Net, A., Marruecos-Sant L (eds): Traumatismo Craneoencefálico Grave. Barcelona, SpringerVerlag, 1996, pp 260-275.

3. Avezaat, C.J.J., van Eijndhoven, J.H.M., Wyper, D.J.: Cerebrospinal fluid pressure and intracranial volume-pressure relationships. J Neurol Neurosurg Psychiatry 1979; 42: 687700 .

4. Bayr, H., Clark, R.S.B., Kochaneck, P.: Promising strategies to minimize secondary brain damage after head trauma. Crit Care Med 1 (Suppl) 2003: S112-S117.

5. Bullock, R., Chesnut, R.M., Clifton, G., Ghajar, J., Marion, D.W., Narayan, R.K., Newell, D.W., Pitts, L.H., Rosner, M.J., Wilberger, J.W.: Guidelines for the management of severe head injury. Brain Trauma Foundation. Eur J Emerg Med 1996; 3: 109-127.

6. Chopp, H., Portnoy, H.D.: Systems analysis of intracranial pressure. Comparison with volume-pressure test and CSFpulse amplitude analysis. J Neurosurg 1980; 53: 516-527.

7. Damaraju, S.C., Rajshekhar, V., Chandy, M.J.: Validation study of a central venous pressure-based protocol for the management of neurosurgical patients with hyponatremia and natriuresis. Neurosurgery 1997; 40: 312-317

8. Dearden, N.M.: Benefits and pitfalls of jugular bulb 
venous oxygen saturation monitoring, en Tsubokawa, T., Marmarou, A., Robertson, C., Teasdale, G., (eds): Neurochemical Monitoring in the Intensive Care. Tokyo, Springer-Verlag, 1995; pp 87-97.

9. Delmas, J., Delmas, A.: Paleoencéfalo y neoencéfalo, en Masson et Cie (ed): Vías y Centros Nerviosos: Introducción a la Neurología. Barcelona, Toray-Masson, 1965; pp 123-159.

10. Eisenberg, H.M., Frankowski, R.F., Contant, C.F., Marshall, L.F., Walker, M.D.: High-dose barbiturate control of elevated intracranial pressure in patients with severe head injury. J Neurosurg 1988;69: 15-23.

11. Foulkes, M.A., Eisenberg, H.M., Jane, J.A., Marmarou, A., Marshall, L.F.: The traumatic coma data bank: design, methods, and baseline characteristics. J Neurosurg (Suppl) 1991;M75: S8-S13.

12. Gennarelli, T.A.: Cerebral concussion and diffuse brain injuries, en Cooper, P.R., (ed): Head Injury. Baltimore, Williams and Wilkins, 1993; pp 148-153.

13. Graham, D.I.: Neuropathology of head injury, en Narayan, R.K., Wilberger, J.E., Povlishock, J.T., (eds.): Neurotrauma. New York, McGraw-Hill, 1996; pp 43-59.

14. Graham, D.I., Adams, J.H., Gennarelli, T.A.: Pathology of brain damage, en Cooper, P..R., (ed): Head Injury. Baltimore, Williams and Wilkins, 1993; pp 91-113.

15. Hall, E.D.: Free radicals and lipid peroxidation, en Narayan, R.K., Povlishock, J.T., (eds.): Neurotrauma. New York, McGraw-Hill, 1996; pp 1405-1419.

16. Hammond, D.A., Wasserman, B.A.: Diffuse axonal injuries_Pathophysiology and imaging. Neuroimaging Clin $\mathrm{N}$ Am 2002;12: 205-216.

17. Harrigan, M.R.: Cerebral salt wasting syndrome: a review. Neurosurgery 1996;38: 152-160.

18. Hirai, O., Handa, H., Ishikawa, M., Kim, S.H.: Epidural pulse waveform as an indicator of intracranial pressure dynamics. Surg Neurol 1984; 21: 67-74.

19. Hodge, C., Boakye, M.: Biological Plasticity_The future of science in neurosurgery. Neurosurgery 2001; 48: 2-16. 40-

20. Jennett, B., MacMillan, R.: Epidemiology of head injury. Br Med J 1981; 282: 101-104.

21. Jennett, B., Teasdale, G.: Aspects of coma after severe head injury. Lancet 1977; 1: 878-881.

22. Liu, P.R., Robertson, C.S., Valadka, A.: The association between neuronal nitric synthase and neuronal sensitivity in the brain after brain injury. Ann NY Acad Sci 2002; 962: 226-241.

23. Lobato, R.D., Cordobés, F., Rivas, J.J., de la Fuente, M., Montero, A., Bárcena, A., Pérez, C., Cabrera, A., Lamas, E.: Outcome from severe head injury related to the type of intracranial lesion. A computerized tomography study. J Neurosurg 1983; 59: 762-774.

24. Lu, A., Tang, Y., Ran, R., Clark, J.F., Aronow, B.J., Sharp, F.R.: Genomics of the periinfarction cortex after focal ischemia. J Cereb Blood Flow Metab 2003; 23: 786-810.

25. Marshall, L.F., Marshall, S.B., Klauber, M.R., Van Berkum Clark, M., Eisenberg, H., Jane, J.A., Luerssen, Tg., Marmarou, A., Foulkes, M.A.: The diagnosis of head injury requires a classification based on computerized axial tomography. J Neurotrauma 1992; 9 (Suppl): S287-S292.

26. Maset, A.L., Marmarou, A., Ward, J.D., Choi, S., Lutz, H.A., Brooks, D., Moulton, R.J., DeSalles, A., Muizelaar, J.P., Turner, H., et al.: Pressure-volume index in head injury. J Neurosurg 1987; 67: 832-840.

27. Navarro-Gonzalvez, J.A., Arenas, J., Lobato, R.D., Gómez, P., Rodríguez-Arias, C.A.: Levels of nitric oxide are markedly increased in cerebrospinal fluid from patients with severe head injury. Clin Chim Acta2000; 290: 221-222.

28. North, B., Reilly, P.: Raised intracranial pressure. -A clinical guide. Oxford, Heinemann Medical Books, 1990.

29. Oertel, M., Kelly, D.F., Lee, J.H., McArthur, D.L., Glenn, T.C., Vespa, P., Boscardin, W.J., Hovda, D.A., Martin, N.A.: Efficacy of hyperventilation, blood pressure elevation, and metabolic supression therapy in controlling intracranial pressure after head injury. J Neurosurg 2002; 97: 1045-1053.

30. Paolin, A., Nardin, L., Gaetani, P., Rodriguez y Baena, R., Pansarasa, O., Marzatico, F.: Oxidative damage after severe head injury and its relationship to neurological outcome. Neurosurgery 2002; 51: 949-955.

31. Poca, M.A., Sahuquillo, J., Mena, M.P., Vilalta, A., Riveiro, M.: Actualizaciones en los métodos de monitorización cerebral regional en los pacientes neurocríticos: presión tisular de oxígeno, microdiálisis cerebral y técnicas de espectroscopía por infrarrojos. Neurocirugía 2005; 16: 385-410.

32. Polidori, M.C., Mecocci, P., Frei, B.: Plasma vitamin $\mathrm{C}$ levels are decreased and correlates with brain damage in patients with intracranial hemorrhage or head trauma. Stroke 2001; 32: 898-905.

33. Resnick, D.K., Marion, D.W., Carlier, P.: Outcome analysis of patients with severe head injuries and prolonged intracranial hypertension. J Trauma 1997; 42: 1108-1111.

34. Robertson, C.S.: Anaerobic metabolism within the brain failure in head-injuried patients, en Vincent, J.L., Bilhari, D., Holaday, J.W., (eds): Update in Intensive Care and Emergency Medicine, vol 4, Brain Failure. Berlin, SpringerVerlag, 1989; pp 85-102.

35. Robertson, G.L.: Posterior pituitary, en Felig, P., Baxter, J., Broadls, A., Frohman, L.A., (eds): Endocrinology and Metabolism. New York, McGraw-Hill, 1987; pp 338388 .

36. Rodríguez Arias, C.A.: Implicación de la cadena respiratoria en la isquemia-revascularización y su relación con los radicales libres. Variaciones de los complejos I y IV en un modelo experimental de colgajo libre cutáneo. Tesis Doctoral. Universidad de Salamanca. 1997.

37. Rosner, M.J., Rosner, S.D.: CPP management I: Results, en Nagai, H., Kamiya, K., Ishii, S., (eds): Intracranial 
Pressure IX. Tokyo, Springer-Verlag, 1994; pp 218-221.

38. Rosner, M.J., Rosner, S.D.: CPP management II: Optimization of CPP or vasoparalysis does not exist in the living brain?, en Nagai, H., Kamiya, K., Ishii, S., (eds): Intracranial Pressure IX. Tokyo, Springer-Verlag, 1994; pp 221223.

39. Sahuquillo, J., Amorós, S., Santos, A., et al: Does an increase in cerebral perfussion pressure always mean a better oxygenated brain? A study in head-injuried patients. Acta Neurochir (Suppl) 2000; 76: 457-462.

40. Sahuquillo, J., Rodríguez-Baeza, A., Báguena, M., Reina, F., Campos, L., Rubio, E.: Autorregulación cerebral: conceptos fisiopatológicos y metodología para su valoración en el paciente neurotraumatizado. Medicina Intensiva 1996; 20: 69-78.

41. Sakamoto, A., Ogawa, R., Ohnishi, T., Ohnishi, S.T.: Trapping of oxygen free radicals during brain ischemia and reperfusion, en Ohnishi, S.T., Ohnishi, T., (eds.): Central Nervous System Trauma. Research Techniques. Boca Raton, Florida, CRC Press Inc, 1995; pp 445-453.

42. Smith, D.H., Casey, K., McIntosh, T.K.: Pharmacologic therapy for traumatic brain injury: experimental approaches. New Horizons 1995; 3: 562-572.

43. Symon, L.: Pathological regulation in cerebral ischemia, en Wood, J.H., (ed): Cerebral Blood Flow. Physiological and Clinical Aspects. New York, McGraw-Hill, 1987; pp 423424

44. Takashi, T., Kazuya, M., Tomoya, M., Shintaro, Y., Kazufumi, I., Minoru, S.: Optimal temperature for the management of severe traumatic brain injury_ Effect of hypothermia on intracranial pressure, systemic and intracranial dynamics, and metabolism. Neurosurgery 2003; 52: 102-112.

45. Teasdale, G.M., Graham, D.I.: Craniocerebral trauma: protection and retrieval of the neuronal population after injury.
Neurosurgery 1998; 4: 723-738.

46. Ward, J.: Intracranial pressure: its measurement and treatment, en Vincent, J.L. (ed): Yearbook of Intensive Care and Emergency Medicine. New York, Springer Verlag, 1994; pp 631-637.

47. Wilson, J.X., Gelb, A.W.: Free radicals, antioxidants, and neurological injury_ Possible relationship to cerebral protection by anesthetics. J Neurosurg Anesthesiol 2002; 14 : 66-79.

48. Wolf, J.A., Stys, P.K., Lusardi, T., Meaney, D., Smith, D.H.: Traumatic axonal injury induces calcium influx modulated by tetrodotoxin-sensitive sodium channels. J Neurosc 2001; 21: 1923-1930.

49. Wright, D.G., Laureano, R., Victor, M.: Pontine and extrapontine myelinosis. Brain 1979; 102: 361-385.

50. Yablon, S.A.: Postraumatic seizures. Arch Phys Med Rehabil 1993; 74: 983-1001.

51. Zauner, A., Daugherty, W., Bullock, R., Warner, D.: Brain oxygenation and energy metabolism_Part I_Biological function and pathophysiology. Neurosurgery 2002; 51: 289302.

52. Zeuthen, T., Klaerke, D.A.: Transport of water and glycerol in aquaporin 3 is gated by $\mathrm{H}^{+}$. J Biol Chem 1999; 274: 21631-21636.

Bárcena-Orbe, A.; Rodríguez-Arias, C.A.; Rivero-Martín, B.; Cañizal-García, J.M.; Mestre-Moreiro, C.; CalvoPérez, J.C.; Molina-Foncea, A.F.; Casado-Gómez, J.: Revisión del traumatismo craneoencefálico. Neurocirugía 2006; 17: 495-518.

Correspondencia postal: Alejandro Bárcena Orbe. Servicio de Neurocirugía. Hospital Central de la Defensa. Glorieta del ejército s/n. 28047 Madrid. 